\title{
Los que ponen el cuerpo. El profesor de secundaria en la Argentina actual
}

\section{Those who put the body. The high school teacher in Argentina today}

\section{Aqueles que colocam o corpo. O professor do ensino médio na Argentina hoje}

\author{
Emilio Tenti Fanfani ${ }^{1}$
}

\begin{abstract}
RESUMEN
El artículo presenta un análisis de los profesores de enseñanza secundaria en la Argentina, tomando como base la existencia de una crisis en el modelo tradicional de la escuela de esta etapa escolar, lo que sugiere que las condiciones de los profesores y los estudiantes han cambiado, como han cambiado otras condiciones sociales, todavía sin que la escuela tenga acompañado a estos cambios. El artículo utiliza los datos del Censo Nacional de Docentes en Argentina entre 1994 y 2004 y los resultados muestran un amplio panorama de trabajo de los profesores ante los desafíos de la escuela secundaria en la Argentina, sobre todo al señalar que es muy difícil de aislar los impactos generados por un profesor, en particular, en la formación de los estudiantes; que los efectos del trabajo docente en la escuela operan conjuntamente a los factores exógenos; que la valorización y las consecuencias de la formación promovida en la escuela a los estudiantes, a veces sólo se produce en tiempo muy distinto del trabajo escolar. Por último, la obra se cierra con la idea de que los estudiantes y sus familias y los propios profesores no se equivocan con respecto a la imagen que representa un buen maestro. Sucede que el problema de la expansión de
\end{abstract}

1 Investigador principal del Consejo Nacional de Investigaciones Científicas y Técnicas (CONICET) y profesor en la Facultad de Ciencias Sociales de la Universidad de Buenos Aires (UBA). Consultor internacional del Instituto Internacional de Planeamiento de la Educación/United Nations Educational, Scientific and Cultural Organization (IIPE/UNESCO), Sede Regional Buenos Aires, Argentina. E-mail: emilio@iipe-buenosaires.org.ar. 
esta realidad está ligado a las acciones de los sistemas de educación a favor de una expansión de la escolarización, pero sin las condiciones necesarias para ampliar la calidad de la enseñanza.

Palabras clave: trabajo docente; escuela secundária; educación en Argentina.

\begin{abstract}
This article presents an analysis of secondary school teachers in Argentina, considering the existence of a crisis in the traditional model of school of this school stage, suggesting that the conditions of teachers and students have changed, as other social conditions have changed. However, the school haven't accompanied those changes. This article uses data from the National Census of Teachers in Argentina between 1994 and 2004 and the results show a broad overview of teachers' work facing thehigh school challenges in Argentina, especially noting that it's very difficult to isolate the impacts generated by a teacher in particular on students; that the effects of teaching work together with exogenous factors at school; that the recovery and the consequences of the formation promoted to students, sometimes only occur a long time after the school time. Finally, this work closes with the idea that students and their families and teachers themselves usually are not mistaken with the image that represents a good teacher. What occurs is that the expansion problem of this reality is linked to the actions of the education systems in favor of an expansion of schooling, but without the necessary conditions to increase teaching quality.
\end{abstract}

Keywords: Teachers' work; secondary school; education in Argentina.

\title{
RESUMO
}

O artigo apresenta uma análise sobre os docentes da escola secundária argentina, tomando como pano de fundo a existência de uma crise do modelo tradicional da escola desta etapa escolar, sugerindo-se que as condições dos docentes e dos alunos têm mudado, como têm mudado as demais condições sociais, sem que, contudo, a escola secundária tenha acompanhado tais mudanças. O artigo utiliza dados do Censo Nacional dos Docentes da Argentina dos anos de 1994 e 2004 e os resultados mostram um amplo panorama do trabalho docente ante os desafios da escola secundária argentina, destacadamente observando que: é muito difícil isolar os impactos gerados por um docente, em particular na formação dos alunos; que os efeitos do trabalho docente operam em conjunto com fatores exógenos à escola e; que a valorização e as consequências da formação promovida na escola 
para os alunos, por vezes, só ocorre muito tempo após o encerramento do período escolar. Por fim, o trabalho encerra com a ideia de que os alunos e suas famílias e os próprios docentes não se equivocam no que se refere à imagem que representa um bom professor. Ocorre que o problema para a expansão desta realidade se articula com as ações dos sistemas de ensino em favor de uma expansão da escolarização, mas sem as devidas condições para a ampliação da qualidade do trabalho docente.

Palavras-chave: Trabalho docente; escola secundária; educação argentina.

\section{Introducción}

La escuela secundaria es un extraordinario laboratorio social. El colegio es un ámbito donde se presentan con colores muy vivos muchas de las grandes transformaciones que vive la sociedad argentina actual. Todo lo que sucede en la sociedad se siente en las instituciones escolares. Estas se han convertido en una especie de vanguardia de los cambios sociales y por lo tanto constituyen un objeto privilegiado para analizar y entender muchos fenómenos nuevos, en especial en el campo de la construcción de nuevos agentes y relaciones sociales. Más allá del carácter deseable o indeseable de los cambios que se viven, es preciso entender la lógica de su producción y las condiciones sociales que presiden su desarrollo.

La masificación de la enseñanza media contribuyó a constituir este nivel en un lugar privilegiado para el análisis de los cambios sociales y culturales de las sociedades contemporáneas. Para tener una primera idea de la magnitud del proceso de escolarización basta recordar que hace cuarenta años (1970) sólo el $35.6 \%$ de los jóvenes de 15 a 19 años frecuentaba un establecimiento educativo. Treinta años después (en 2001) ese porcentaje subió al 68.5\%.

Este incremento en la escolarización del nivel medio una especie de tendencia que se observa en casi todas las sociedades latinoamericanas. Sin embargo, cuando el nivel alcanza altas tasas de cobertura ( $70 \%$ o más de la franja de edad) comienzan a manifestarse dificultades crecientes para incorporar al tercio que queda afuera. También se vuelve más dificultosa la permanencia de los adolescentes en las instituciones (TEDESCO; LÓPEZ, 2002)2.

2 Según un informe realizado por el IIPE/UNESCO, Sede Regional Buenos Aires realizado con apoyo del Programa de las Naciones Unidas para el Desarrollo - PNUD/Argentina en febrero de 2008 (en prensa) el porcentaje abandono durante el año escolar en las instituciones de nivel medio del país subió de $4.2 \%$ en 2001 a $6.3 \%$ en 2005 . 
Como veremos más adelante, esta masificación de las matrículas fue acompañada por un cambio en su morfología social, por lo tanto, no se trata solamente de constatar que hoy hay muchos más alumnos escolarizados (lo cual es en sí mismo un desafío y un factor que produce ciertas consecuencias, incluso pedagógicas), sino que es preciso reconocer que se trata de otros alumnos. Estos son diferentes de los alumnos de mediados del siglo pasado, tanto por sus características sociales, como por las culturales.

La obligatoriedad de la enseñanza media, decidida por la Ley nacional de educación del año 2007 es un reconocimiento de una tendencia social y al mismo tiempo es un factor que la favorece e impulsa. Como consecuencia de estos cambios, la escuela media de hoy no tiene mucho que ver, como objeto y experiencia social, con la escuela media del pasado, en especial con el "colegio secundario", tal como lo imaginaron y diseñaron sus padres fundadores, a fines del siglo XIX y principios del XX.

Los profesores de enseñanza media no sólo son más numerosos que en el pasado. Ellos tampoco son los mismos. Y son ellos los que le están poniendo el cuerpo a los nuevos problemas derivados de los cambios de sentido de la educación media. Ellos también son más numerosos y son diferentes de sus colegas de la etapa del secundario elitista y selectivo. No es fácil medir la distancia entre unos y otros porque no existen datos comparativos confiables, pero quienes vivieron el secundario de mediados del siglo XX y observan lo que sucede con los docentes del momento actual tienen muchas razones para suponer razonablemente que estamos en presencia de otro cuerpo docente.

Los cambios sociales y culturales de la población estudiantil tienen efecto sobre la propia conformación del cuerpo docente de enseñanza media. Los docentes de media de hoy, como agentes sociales no son "lo mismo" que los de ayer, cuando el nivel medio tenía una racionalidad social claramente selectiva y era un lugar que acogía a los hijos de las clases más acomodadas (los "herederos" como los calificó la tradición sociológica francesa) y a los hijos de las clases sociales más desposeídas que pasaban por una serie de filtros meritocráticos y en muchos casos eran "becados" por el Estado o por particulares para favorecer su asenso social a través de la educación.

Los profesores de la vieja educación secundaria tenían un perfil sociocultural muy diverso al actual. Entre otras cosas y más allá de su origen y posición en la estructura social y su capital escolar (muchos de ellos universitarios), el contacto cotidiano con los hijos de las clases más privilegiadas de la sociedad les proveía de un prestigio "por contagio", derivado de la proximidad física con esas clases (CAVALLI, 2003).

En síntesis, nuestro análisis está teñido por un supuesto de fondo: la existencia de una crisis del sentido tradicional del colegio secundario en la 
Argentina y de los principales dispositivos institucionales y pedagógicos "clásicos", es decir, típicos de su momento fundacional y que orientaron sus primeras etapas de desarrollo (TENTI FANFANI, 2003). En relación con lo anterior, consideramos que el modelo tradicional todavía no ha sido sustituido por otro, al menos en lo que respecta al grueso de las instituciones de enseñanza media del país. En otras palabras, el cambio de las condiciones sociales que hicieron posible el modelo tradicional no ha generado todavía, a nivel del conjunto del sistema, un nuevo proyecto adecuado a las nuevas circunstancias y exigencias sociales. Como no podía ser de otra manera, han cambiado tanto la experiencia de docentes y alumnos de enseñanza media como la relación de las prácticas y productos escolares, con la trayectoria social de las nuevas generaciones y el desarrollo de la sociedad ${ }^{3}$.

Con base en estos supuestos, el texto que sigue a continuación contiene un análisis de algunas características objetivas (posición en la estructura social, formación inicial y permanente, condiciones de trabajo) y subjetivas (opiniones y representaciones acerca de su rol, los valores de los jóvenes, los problemas en el aula, etc.) de los docentes de enseñanza media del país. Estas nuevas características configuran a la docencia de enseñanza media como un cuerpo colectivo extremadamente diversificado. Por otra parte se pone especial énfasis en algunos nuevos problemas que deben gestionar en el desempeño de su función específica en las instituciones escolares (el "desinterés" de los alumnos en los contenidos del programa escolar, los problemas de construcción de la autoridad docente, etc.) y que se derivan de las nuevas configuraciones socioculturales que caracterizan a los adolescentes escolarizados. Por último se incluyen algunas reflexiones acerca del docente como "artista ejecutante" y las dificultades inherentes a la evaluación de su desempeño.

\section{Sentido y valor de la enseñanza media en el mundo de hoy}

No es preciso abundar en argumentos para mostrar que la enseñanza media de hoy tiene un significado distinto al que tenía en el proyecto fundacional de los sistemas educativos occidentales. En un principio se trataba era una antesala

3 La mayoría de las transformaciones que se registran en los dispositivos institucionales y en los modos de hacer las cosas en la mayoría de los colegios secundarios no obedecen a planes o reformas intencionales sino que son un "efecto de estructura" (la masificación, la escasez de recursos, cambios en la estructura social, cultural, etc.) o bien un caso paradigmático del conocido fenómeno de las "consecuencias no intencionales de la acción". 
de los estudios universitarios (y de ciertas posiciones en las burocracias públicas y privadas emergentes) y como tal estaba reservada sólo a los herederos, es decir a los hijos de las clases dominantes y a algunos pobres meritorios (los "becarios"). Hoy la enseñanza media es más que eso. En verdad es otra cosa. Se trata de la última etapa de la escolaridad obligatoria. Vale no sólo como sendero que conduce a los estudios superiores (valor que conserva), sino que es algo así como el nuevo piso de la escolaridad obligatoria que en todas partes tiende a prolongarse hasta los 17 o 18 años de vida de los individuos. En las condiciones actuales, la llamada enseñanza media es una enseñanza "final" (un "techo") para la mayoría de la población y un momento de un proceso de formación de una minoría, que tiende a prolongarse a lo largo de toda su trayectoria vital (educación superior y permanente).

Esta nueva racionalidad cambia el sentido y afecta los viejos "modo de hacer las cosas" en las instituciones. En un principio, cuando se trataba de formar elites, la lógica de la selección impregnaba el quehacer de docentes y alumnos. La carrera escolar era como una carrera de obstáculos. Los "más capaces" de superarlos llegaban al final y adquirían el derecho de entrada a la universidad (en un principio no tenía sentido ninguna "prueba de ingreso" a la educación superior, la condición de acceso era el título de bachiller). La práctica sistemática de los exámenes permitía distinguir a los exitosos de los fracasados. El fracaso era un fenómeno habitual y esperado en la experiencia escolar. Siempre los llamados eran más que los elegidos y todos los "jugadores" (maestros, familias, alumnos) conocían y compartían esta regla del juego y aceptaban sus desenlaces. El colegio secundario los premios y castigos se asignaban según el "talento", el "esfuerzo" y la ideología del mérito.

Cuando la enseñanza media se convierte en obligatoria, todos estos dispositivos dejan de tener sentido y si persisten en su accionar, son una fuente de contradicción y conflicto. Hoy la permanencia de los adolescentes en la escuela ya no es algo aleatorio o discrecional. Ni los alumnos ni los padres, ni los agentes escolares están en condiciones de determinar la inclusión o la exclusión escolar. Todos los adolescentes deben estar en la escuela. Este es un mandato de la ley (la escolarización, al menos en el nivel básico fue siempre un derecho y una obligación) y al mismo tiempo un mandato social (del mercado de trabajo). Hoy la institución ha perdido la capacidad de imponer reglas que determinen la permanencia o el abandono escolar. En principio, todos deben ser contenidos e "incluidos" en la institución.

Esta disposición determina la demanda y afecta fuertemente a la oferta. Por una parte las familias y los jóvenes deben saber que ir o no ir a la escuela, al menos teóricamente, ya no es una cuestión de elección discrecional. Y en cuanto a la instancia responsable de garantizar el cumplimiento de la obligatoriedad, 
es decir, al Estado, éste se ve obligado a ampliar la oferta escolar y a garantizar las condiciones sociales del aprendizaje de todos. De allí la tendencia intervenir mediante programas de becas, subsidios y apoyo a los jóvenes y sus familias.

Pero el cambio de sentido y la obligatoriedad también determinan una serie de transformaciones en los dispositivos y procesos institucionales. El examen y la evaluación ya no pueden cumplir una función selectiva, sino estrictamente pedagógica y los problemas de aprendizaje ya no se resuelven por la vía fácil y corta de la repetición y la exclusión. Lo mismo puede decirse de los "problemas de conducta y disciplina". Sin embargo, las adaptaciones de las instituciones y las mentalidades no son simples efectos automáticos de las transformaciones estructurales y legales ${ }^{4}$. Por lo tanto la contradicción tiende a transformarse en conflicto y el desajuste entre las predisposiciones y los marcos normativos tiende a provocar el malestar. Por eso la educación para los adolescentes y los jóvenes se convierte en el eslabón más crítico de las políticas educativas nacionales. Y a su vez, el trabajo del docente de media se vuelve cada vez más conflictivo y desafiante al mismo tiempo.

\section{El profesor de secundaria: un agente entre dos mundos}

El profesor de enseñanza media de hoy está entre dos mundos. Por una parte tiene la misión de transmitir a las nuevas generaciones una cultura que en gran parte no es de hoy, sino que tiene siglos de existencia. Desde este punto de vista el docente, en tanto adulto representa una tradición y la historia de una sociedad y una cultura (en nuestro caso la cultura de Occidente). Pero ese mismo docente comparte gran parte de su vida con adolescentes y jóvenes, que representan lo nuevo y el futuro. Ellos no solamente son portadores de contemporaneidad sino que también son y representan lo nuevo y el futuro. El diálogo docente alumno, hoy es el diálogo entre dos mundos y dos culturas. Pero este diálogo y las condiciones (institucionales, sociales, etc.) en que se desarrolla no siempre es pacífico y muchas veces es fuente de frustraciones y malestares para ambas partes. La relación docente alumno en la enseñanza media no siempre es feliz sino que está lleno de contradicciones y muchas veces de conflictos más o menos intensos y duraderos.

4 En el caso de la Argentina son habituales los conflictos y discusiones acerca de la pertinencia de aumentar el nivel de exigencia en los estudios, evitar el "facilismo en los examenes", restaurar viejos mecanismos disciplinarios tales como las amonestaciones y la expulsión de los alumnos para garantizar el orden en los establecimientos, etc. 
Según el sociólogo italiano Alessandro Cavalli (2003), los esquemas temporales de los profesores son diferentes de los de los jóvenes. Estos últimos han sido constituidos por una cultura del presente que ocupar toda la escena temporal. Mientras que las condiciones sociales en que se desarrollaron los adultos favorecieron una conciencia temporal donde el pasado (como memoria, como raíz, como antecedente, etc.) y el futuro (como proyecto, como ideal, como utopía, etc.) tendían a dominar sobre el presente, las nuevas generaciones se construyen a partir de una compresión del tiempo en el presente que les vuelve difícil interesarse por el pasado y hasta proyectar su propia vida en el futuro. En este contexto, el presente tiende a dominar como fuente de interés y sentido para las nuevas generaciones. Es como si los niños y adolescentes fueran una especie de vanguardia de las transformaciones sociales y culturales, mientras que los docentes (adultos) son los representantes de un mundo que tiende a desdibujarse.

Sin embargo, hay que desconfiar de estas imágenes demasiado genéricas. Esta especie de "choque de las civilizaciones" puede inducir a errores de interpretaron, como todas las generalidades abstractas y por lo abusivas. Estas tienden a la indiferencia por las diferencias que cada vez más caracterizan a nuestras sociedades. En efecto, para algunos, por ejemplo para esa fracción de las clases dominantes que están destinados a "heredar" las posiciones de dominación, la cultura de la sociedad de consumo y su imperio del presente y el "momento actual" no son un obstáculo para sus estrategias objetivas de reproducción social. Por el contrario, ellos están en condiciones de hacer lo que tienen que hacer para reproducir sus privilegios.

Los hijos de las clases más desposeídas y subordinadas, por el contrario, también viven en el presente, porque no tienen futuro en el sentido literal del término. Esto quiere decir que desde el punto de vista objetivo no hay posiciones sociales que los estén esperando para cuando ellos lleguen a la condición de adulto. En muchos casos no los espera ni siquiera un empleo decente que les garantice la satisfacción de sus necesidades básicas y las de su familia. Por eso, aún cuando el imperio del presente pareciera ser una característica común de los contemporáneos, desde el punto de vista social, tiene consecuencias extremadamente diferentes. Vivimos en un presente desigual que a algunos les absorbe todos los recursos de que disponen, incluso sus energías y pasiones. Otros, en cambio, pueden hacer un uso intensivo de las ventajas y placeres del presente, sin hipotecar con ello sus posibilidades de futuro ${ }^{5}$.

5 Marx decía que el propietario es "heredado" por la herencia. En otras palabras, los herederos cuando se apropian de la herencia (de bienes materiales y simbólicos) son apropiados por ella, la cual les impone determinadas conductas (de conservación, de cálculo, de cuidado de lo heredado) que tienen que ver con la reproducción social. El que nada tiene no está "obligado" por el futuro, y muchas veces tampoco por el pasado, como es el caso de ciertas culturas dominadas que también han sido expropiadas también de su memoria y su cultura. 
Por todo lo anterior, este síndrome de "desestructuración temporal" (como lo denomina Cavalli) tiene consecuencias particularmente dramáticas en los grupos sociales más excluidos y es una fuente de tensiones, desencuentros e incomprensiones en la relación entre las generaciones que se desarrolla en el interior de las aulas y de las que volveremos a hablar más adelante.

Además de esta diferencia fundamental en relación con la percepción temporal, los jóvenes y adolescentes se han constituido en "clases de edad", no solo con derechos, sino también con sus propios consumos culturales y materiales. La sociedad de consumo y las estrategias de marketing han contribuido al ensanchamiento de la brecha entre las generaciones. En primer lugar, construyendo actores colectivos, por lo general consumidores, diferenciados. La "targetización" de los consumidores (SIMONE, 2008) favoreció los consumos diferenciados por clases de edad. Toda una serie de productos de la industria (la indumentaria, los juguetes, los alimentos, etc. y los servicios (lugares de esparcimiento y turismo, géneros y grupos musicales, películas, sitios de internet, programas y canales de televisión, etc.) construyen grupos de edad cada vez más específicos y contribuyen de esta manera a fragmentar la sociedad y a volver cada vez más difícil el dialogo y la convivencia entre las generaciones. El programa escolar fue hecho para uniformar y homogeneizar (efecto de socialización), pero hoy sus efectos son extremadamente débiles en relación con el poder preformativo de la publicidad y los consumos culturales no escolares.

No debe extrañar pues que los adolescentes tiendan a "hablar" lenguajes diversos del que hablan la escuela (con sus programas, sus materias, sus cursos, sus reglas, etc.) y el docente. Pero el lenguaje también es un modo de ver el mundo y de jerarquizar los objetos sociales y de ordenar preferencias y valoraciones.

El programa escolar, esto es, lo que el profesor tiene que transmitir a las nuevas generaciones, muchas veces no coincide con los intereses y pasiones de los adolescentes, las cuales se canalizan mejor en otros ámbitos culturales como por ejemplo los que les ofrecen las nuevas tecnologías de la comunicación y la información.

El consumo cultural de los jóvenes se mueve por otros carriles, se orientan por otros intereses y otras pasiones muchas veces demasiado alejadas de lo que ofrece el programa escolar con sus materias y disciplinas.

En el caso de la Argentina, como en el de otras sociedades de mediano desarrollo, la cuestión cultural no es la única fuente de dificultad en la relación entre alumnos y docentes de secundaria. Las fuertes desigualdades sociales también atentan contra la escolarización y los aprendizajes. En muchos casos, el ir a la escuela tiene un costo directo y "de oportunidad" demasiado elevado para los adolescentes y sus familias. Si a esto se agrega que en la valoración del costo también interviene el beneficio que se puede esperar del colegio y de 
los títulos que otorga la cuestión se vuelve todavía más complicada para los sectores populares.

Por otra parte, en todos los países de América Latina la escuela media se ha masificado, pero este crecimiento de los títulos escolares no ha sido acompañado por un crecimiento proporcional de los empleos y ocupaciones que ofrece el mercado de trabajo. Este desequilibrio entre masificación (desigual) de la escolaridad y la consecuente proliferación de los títulos (de bachiller, perito mercantil, etc.) frente a un mercado de trabajo restringido constituye un factor de desestímulo al esfuerzo escolar. El vínculo esfuerzo/éxito escolar/empleo que en términos generales existía en la etapa de la escolaridad media selectiva y elitista, hoy se ha roto. La escuela "ascensor social" dejó de funcionar y tanto los jóvenes como las familias han tomado conciencia del asunto. Cuando los grupos sociales subordinados alcanzan el tan ansiado título de estudios secundarios completos, por una paradoja social, este deja de tener el valor que solía tener en otro estadio del desarrollo de la sociedad y el sistema escolar. En este contexto no debe sorprender la frecuencia del desencanto de muchos sectores sociales frente a lo que la escuela actual puede ofrecer como "premio" al esfuerzo y al trabajo pedagógico.

Por lo tanto los alumnos y los docentes de la escuela secundaria actual no se parecen mucho a los de antes. Durante los últimos 30 años se han incorporado al colegio los hijos de familias que habían estado excluidas de este nivel "que no había sido hecho para todos". La masificación y el cambio de la morfología social del colegio y el tipo de oferta que se desplegó para hacer frente a esta demanda produjeron una desestruturación del sentido del secundario (para la sociedad, para las familias, para los alumnos, para los docentes) y de los dispositivos pedagógicos y organizacionales tradicionales.

El Estado respondió a la demanda de escuela media a través de una política de expansión de la escolaridad que en muchos casos contribuyó a fragmentar el sistema y a mantener las formas (los programas, las reglas, etc.) pero no los contenidos de la experiencia escolar. Lo que resultó de este proceso es un sistema educativo extremadamente segmentado (TIRAMONTI; ZIEGLER, 2008) y jerarquizado. Mientras los hijos de las clases dominantes frecuentan instituciones fuertes y distinguidas (es decir, ricas en recursos, "con historia", con "prestigio" y socialmente valoradas), la mayoría concurre a establecimientos "de masas", muy indiferenciados, por lo general pobres, en especial cuando se los compara con los recursos (de tiempo, de infraestructura, de materiales didácticos, equipamientos informáticos, etc.) de que disponen los colegios más prestigiosos.

Las evaluaciones del rendimiento en los aprendizajes desarrollados por alumnos que concurren a este nivel son también muy diferenciados. Tal como lo muestran los estudios más serios realizados en la Argentina (CERVINI, 2003) 
la mayoría de las diferencias en el aprendizaje en competencias básicas como la lengua y las matemáticas obedecen a diferencias en el capital económico, social y cultual de las familias de los alumnos, como a las diferencias en la calidad de las instituciones (medida por los recursos de que disponen) donde desarrollan su escolaridad.

Todas estas transformaciones son "vividas" (aunque no siempre igualmente comprendidas) por los profesores de enseñanza media. Son ellos los que "ponen el cuerpo" a las nuevas situaciones que enfrentan en su trabajo cotidiano y al empobrecimiento institucional del colegio de enseñanza secundaria.

Entre otras cosas, y como se verá más adelante, están cada vez más solo para hacer frente a los nuevos desafíos que implica la producción de esa dosis necesaria de autoridad y legitimidad que necesitan para llevar a cabo su tarea en las aulas. Pero de esto vamos a hablar más adelante, cuando describamos los nuevos desafíos del profesor de enseñanza media. Pero veamos antes quiénes son los profesores de enseñanza media en la Argentina actual.

\section{Quiénes son los profesores de media}

Los objetos sociales no son esencias, por lo tanto sería equivocado presentar al profesorado de enseñanza media como si tuviera una realidad sustancial que pudiera ser definida a partir de la simple pregunta ¿Qué es un profesor de enseñanza media? En estos casos es preciso poner en práctica lo que en ciencias sociales se denomina "el principio relacional" que nos invita a buscar la especificidad de un elemento social (acontecimiento, institución, agente, etc.) en la relación que mantiene con los otros, dentro del espacio social en que está situado.

El profesor de secundaria es un colectivo extremadamente variado, pero que "se diferencia" del maestro de primaria. Por lo tanto puede resultar útil comparar ciertas características de los docentes en función del nivel en que se desempeñan para comprender lo que es específico del docente de media. Para los fines de este artículo nos limitaremos a describir brevemente algunas características sociodemográficas, de posición en la estructura social, y de formación e incorporación al mercado de trabajo de los docentes de nivel medio en la Argentina. Terminaremos esta descripción con un breve análisis de los problemas más frecuentemente percibidos por los docentes en el desarrollo de su trabajo en las aulas. 
a) Masificación de la enseñanza media y masificación del cuerpo docente

El cuerpo de docentes de media ha tenido un crecimiento proporcional a la población escolarizada. En otras palabras, se trata de una ocupación que creció significativamente durante los últimos años.

En 1994, al inicio de la reforma educativa iniciada con la sanción de la Ley Federal de Educación en la Argentina habían 303.486 docentes en el nivel medio. Diez años después (2004) esa cifra llega a 432.096 ${ }^{6}$. En otras palabras, en diez años el número de profesores de secundaria tuvo un crecimiento del $42.2 \%$.

El 70\% de ellos son mujeres, pero se trata de un colectivo menos feminizado que el de enseñanza primaria (en este nivel sólo el 7\% es varón).

En general, los docentes varones tienen una estructura de edad más joven que las mujeres, pero esta diferencia es más marcada entre los maestros que entre los profesores. Entre los segundos la estructura de edades de ambos géneros es más parecida, aunque los docentes de menos de 35 años, tienen un mayor peso relativo entre los varones. En el mismo sentido, entre las profesoras mujeres la proporción de 45 años y más es más elevada que entre los hombres. Es probable que con el paso del tiempo, los hombres tengan más oportunidades laborales extraescolares que las mujeres. No hay que olvidar que una cierta proporción de docentes poseen títulos universitarios no docentes, que los habilitan para realizar tareas fuera del ámbito educativo.

Según los datos de los censos docentes en 1994, el 60\% de los docentes de media trabajaba en el sector público y $23 \%$ lo hacía en el privado (el resto $-17 \%$ - lo hacía en ambos sectores). Diez años después las proporciones son semejantes, con un pequeño incremento de aquellos que solo trabajan en el sector público $(64 \%)$.

Otro hecho a tener en cuenta es que la mayor parte del crecimiento de la escolarización en el nivel medio se registró en el sector público y por el sector privado subsidiado por el Estado. No es difícil explicar este hecho. Basta recordar que esta ampliación de oportunidades educativas permitió acceder al nivel medio a grupos que antes estaban excluidos de este nivel y que forman parte de las categorías sociales más desposeídas de la población que, por definición, no disponen de los recursos necesarios como para "comprar" educación privada (en el sentido estricto de la expresión, es decir, sin financiamiento estatal).

6 Los datos corresponden a los censos nacionales docentes de 1994 y 2004 respectivamente. Las cifras de este segundo año corresponden a profesores de $8^{\circ}, 9^{\circ}$ de EGB y Polimodal. 
b) Los docentes de media: su posición en la estructura social ${ }^{7}$

Es importante preguntarse acerca del origen y el lugar que ocupan los profesores en la estructura social del país. La posición social de los profesores contribuye a definir el horizonte de posibilidades de progreso profesional, en la medida que la formación permanente constituye una inversión que requiere de capacidades y recursos. Pero no sólo es importante preguntarse por el lugar que ocupan en la estructura social del presente, sino también por su origen social, es decir, por la posición que ocupaban sus padres cuando ellos fueron niños. Es bien sabido que la relación con la cultura no se adquiere sólo mediante la escolarización. Los padres no sólo transmiten a sus hijos una herencia material (cuando tienen las posibilidades de hacerlo) sino también una herencia cultural, es decir una relación con la cultura, el lenguaje que constituyen como una base que condiciona gran parte de las formaciones posteriores. Por último, el análisis estructural de la posición y el origen social debe complementarse con una perspectiva dinámica o de proceso que tiene que ver con la trayectoria (estable, ascendente o descendente) durante el ciclo de vida de los profesores. No es lo mismo "venir de abajo" y encontrarse en la mitad de arriba de la pirámide social, que la situación inversa. La experiencia o vivencia del tránsito o de la inmovilidad determina también actitudes y predisposiciones culturales que se manifiestan en diversos ámbitos de la existencia social (la política, la visión del futuro, etc.).

Un primer dato que nos provee un indicio acerca de esta cuestión es el lugar que ocupan en términos de posición en la estructura quintílica del ingreso per capita. Las cifras muestran que los profesores de enseñanza media, en general ocupan posiciones más aventajadas en relación con el promedio de los hogares argentinos. Sólo el 2.3\% estaba en el quintil de ingresos más pobres del país. En cambio, están sobre representados en el quintil más rico, ya que ocupan esa posición el $28.4 \%$ de los profesores (Anexo, Cuadro 1).

Si se los compara con sus colegas del nivel primario, los profesores tienen un mejor posicionamiento en la estructura de la distribución del ingreso. Las diferencias son significativas ya que son mucho menos en el quintil de ingresos más pobre (2.3\% contra el $9.1 \%$ de los maestros) mientras que el porcentaje de quienes están situados en el quintil más rico (28.4\%) es sensiblemente más alto que el porcentaje de maestros que están en la misma posición (14.6\%).

7 En este apartado utilizaremos la información producida en el marco del Programa de Investigación sobre Profesionalización de los Docentes que se desarrolla en el IIPE/UNESCO. Las cifras citadas en este apartado corresponden a la encuesta a docentes realizada en la Argentina durante el año 2000. La misma consistió en la aplicación de un cuestionario a una muestra representativa nacional y regional de docentes de nivel primario y medio de áreas urbanas. Para más información ver Tenti Fanfani (2005). 
Estas diferencias de ingreso en favor de los profesores se manifiesta también en la mayor frecuencia en la posesión de ciertos bienes de consumo durable tales como el automóvil, la disposición de una PC en su domicilio o la conexión de internet en la casa (Anexo, Cuadro 2). Al mismo tiempo, en este como en otros casos se observa una significativa variación entre las regiones. Las diferencias en la riqueza relativa de los territorios que componen el país se expresa también en el acceso desigual que tienen los profesores a una serie de bienes y servicios estratégicos no solo para determinar las condiciones generales de vida, sino también el acceso a la cultura y la formación permanente de los docentes.

Si se construye un índice de nivel socioeconómico con base en el capital educativo del jefe del hogar (años de escolaridad) y los bienes y servicios de consumo durable disponibles se observa que sólo el 15.6\% de los profesores están en un nivel que podría definirse como "bajo", mientras que entre los maestros este porcentaje llega al doble (36.4\%). La misma diferencia, pero en sentido inverso se manifiesta cuando se comparan los porcentajes de profesores (34.4\%) y maestros (14.9\%) que se clasifican en el nivel "alto" (Cuadro 3 del Anexo).

La posición que ocupan lo docentes de media en la estructura de distribución del ingreso constituye un factor determinante de la probabilidad de vivir en hogares con ingresos por debajo de la línea de la pobreza. En el año 2000 el 4.2\% de los profesores de media estaban en esta condición. A su vez, este porcentaje casi se triplica entre los maestros de primaria (11.6\%). La probabilidad que tienen los profesores de vivir en hogares con pobreza se triplica en regiones tales como el noroeste y el noreste del país, mientras que cae significativamente en la región pampeada, la Patagonia. (Ver Cuadro 4 del Anexo). Por último, la condición de pobreza de los profesores aumenta a medida que el salario docente constituye una proporción significativa del ingreso total disponible en sus hogares.

La percepción de pobreza es un factor subjetivo a tener en cuenta. Aquí también los profesores de media se distinguen de sus colegas de primaria. Mientras que entre estos últimos $52 \%$ creía que vivía en un hogar pobre, sólo el $23 \%$ de los profesores manifestaron vivir en esta condición.

El origen social de los profesores de media es más elevado que el de los maestros de primaria. La gran mayoría de ellos alcanzó un nivel de escolaridad mayor que el de sus padres. Si se toma el capital escolar de los padres como un indicador de la situación social de los mismos, se observa que solo una minoría de los docentes de secundaria (16.2\%) provienen de hogares cuyos padres tienen un promedio de escolaridad bajo (sin instrucción o primaria incompleta). Por otra parte casi el $40 \%$ de los profesores vienen de familias cuyos padres tienen secundaria completa y/o educación superior). Esta cifra cae al $26.7 \%$ entre los maestros de primaria. 
Por último, las diferencias en el origen social de los profesores y maestros pareciera determinar distintas percepciones al momento de evaluar su posición actual en la estructura social comparada con la que tenían sus padres cuando ellos eran niños. En efecto, en ambos grupos la primera minoría sentía en el año 200 que estaba "peor" que sus padres. Pero esta tendencia es menos marcada entre los profesores ya que la proporción de los vivieron esta situación de "decadencia" social es casi igual a la que vivieron la experiencia contraria (decían en el año 200 que estaban "mejor" que sus padres) (Cuadro 5 del Anexo).

En síntesis, cuando se los compara con los maestros, los profesores de enseñanza media, en general provienen de hogares con mayor capital cultural, están mejor posicionados en la estructura social, con todas las ventajas asociadas y se han vivido con menor frecuencia las dolorosas experiencias de descenso social.

c) Formación de los profesores e incorporación al trabajo docente

Las profesoras tienen un perfil de formación diferente de sus colegas varones. Según la encuesta del IIPE (2000), 15.5\% de las mujeres tienen título de maestra normal nacional (sólo 1.9\% en el caso de los varones). Además 51.5\% es profesora de enseñanza media (36.6\% entre los varones). En cambio el título universitario no docente (se trata de graduados de diversas disciplinas) es mucho más frecuente entre los profesores (23.4\%) que entre las profesoras (10.5\%). También entre los varones es más frecuente el poseer "otro título no docente" $(16.5 \%)$. Entre las mujeres el porcentaje cae al 3.9\%. Por lo tanto la tradición del normalismo argentino está más presente entre las mujeres que entre los varones, o lo que es lo mismo, éstos últimos tienen menos formación pedagógica formal que las primeras. De hecho prácticamente la mitad de los profesores varones no tienen un título docente. Esto quiere decir que" aprendieron el arte de la enseñanza" en a través de la experiencia, primero como alumnos y luego como docentes o bien haciendo cursos, seminarios, etc. Sin embargo es difícil decir hasta qué punto este hecho incide sobre el estilo de trabajo en las aulas o sobre el aprendizaje de los alumnos.

$\mathrm{Al}$ momento de la encuesta, el $20 \%$ de los profesores de enseñanza media manifestó que estaba cursando una carrera de dos o más años de duración. Como es lógico, la inversión educativa es más frecuente entre los profesores más jóvenes (menores de 35 años).

Al igual que los maestros, los profesores tienen una inserción muy temprana al mercado de trabajo docente. En efecto, un cuarto de ellos manifestó que se incorporó a la docencia "antes de recibirse". Por otro lado, se observa que la inserción precoz es más frecuente entre los graduados recientes $(33.1 \%$ entre los graduados en 1990-2000) que entre los graduados en décadas anteriores (20.6\% en el grupo de graduados entre 1976 y 1983). 
Por lo tanto, el déficit observado en cuanto a la formación pedagógica formal y la inserción temprana en el mercado de trabajo docente constituyen indicadores preocupantes en relación con las competencias y conocimientos que se suponen necesarios para ejercer la función docente. Es probable que esta formación incompleta de muchos docentes de media se origine en el tipo de respuesta que la sociedad argentina dio a la demanda creciente de escolarización de los adolescentes.

d) Percepción de situaciones como problemáticas

Muchos son los problemas que enfrentan los docentes de enseñanza media en un contexto de profundas transformaciones sociales y en medio de un proceso notable de masificación del nivel en la Argentina de las últimas dos décadas.

Maestros y profesores tienen problemas comunes. Los datos de la encuesta del año 2000 (IIPE/UNESCO, 2000) muestran que "la falta de tiempo" es una queja compartida por maestros y profesores (Cuadro 6 del Anexo). Sin embargo hay situaciones problemáticas que aparecen con mayor frecuencia entre los profesores de enseñanza media. Unas tienen que ver con dimensiones de la política y gestión de la educación, tales como la "falta de definiciones y objetivos claros" y "la disponibilidad de ámbitos de asesoramiento y supervisión". El primero tiene que ver con la crisis de sentido que afecta particularmente a la enseñanza media. El segundo con la insuficiencia de los apoyos y recursos que el sistema educativo ofrece a los docentes para ayudarlos a resolver situaciones que son radicalmente novedosas y para cuya resolución los docentes no están debidamente equipados en su formación inicial.

La evaluación y la relación con los padres son problemas más frecuentemente percibidos por los profesores que por sus colegas de la escuela primaria. La evaluación es ya de por si un problema más conflictivo cuando se trata de adolescentes, en la medida que éstos están en condiciones de opinar, criticar, exigir y cuestionar tanto las modalidades de evaluación como sus resultados. A su vez, todo parece indicar que los padres están en mejores condiciones de acompañar la escolaridad de los niños en la escuela. Cuando se trata de adolescentes muchas veces las familias se alejan del colegio y delegan la educación y socialización de sus hijos en manos de la institución escolar. Por eso la relación (muchas veces ausente) de los profesores con los padres se constituye en un tema (el 35.9\% de los profesores declara que lo es) de difícil resolución para los profesores de media.

Por último, es sintomático que más de la mitad de los profesores $(53.2 \%)$ manifieste que "las características sociales de los alumnos" son una fuente de 
problemas. No hay que olvidar que durante las últimas décadas los "pobres y excluidos" se incorporaron al colegio. Las múltiples expresiones de la "cuestión social" se hicieron presente en la vida cotidiana de los establecimientos y pusieron en crisis muchos mecanismos y dispositivos pedagógicos tales como el ritmo de trabajo, la evaluación, la autoridad del docente, el manejo de la disciplina y el orden, etc.) que sirvieron para gestionar la clase y que hoy ya están superados por las nuevas situaciones.

Dada la complejidad de los problemas que deben administrar los profesores en los colegios, no debe llamar la atención que trabajen más tiempo fuera del establecimiento que sus colegas de primaria. Mientras estos últimos manifiestan trabajar en promedio casi 25 horas por semana fuera de la escuela, los profesores trabajan 31 (IIPE/UNESCO, 2000). Es probable que en esas horas los profesores hayan contado el tiempo de transporte, ya que casi tres de cada cuatro trabaja en más de un establecimiento e incluso $37 \%$ de ellos trabaja en 3 o más establecimientos. En cambio, el $66.5 \%$ de sus colegas de primaria trabajan en un solo establecimiento, un cuarto lo hace en dos y solo una minoría de menos del 10\% lo hace en tres o más.

\section{Una categoría social cada vez más diversificada y fragmentada}

Los pocos datos citados proveen algunas evidencias acerca del proceso de diversificación del cuerpo de docentes de enseñanza media. Los cambios en la sociedad y el crecimiento sostenido de la escolarización de las nuevas generaciones están produciendo impactos en la configuración social del cuerpo docente.

Donde más se pueden percibir las huellas más evidentes de la transformación es en el cuerpo de profesores de la enseñanza media. Esta es la que ha vivido los procesos de crecimiento más recientes y acelerados. El cuerpo de profesores de secundario siempre fue más diversificado que el de primario, pero a los viejos factores de diferenciación se agregan otros, más recientes.

A modo indicativo pueden enunciarse los siguientes factores (viejos y nuevos) de diversificación de esta importante categoría ocupacional.

a) Un primer factor de diferenciación es el que tiene que ver con la formación. En la escuela media conviven profesores con formación exclusiva en un campo del saber y profesores que además, poseen formación especifica en 
cuestiones pedagógicas y didácticas ${ }^{8}$. Así en una misma institución trabajan uno al lado del otro contadores y/abogados que dictan cursos de contabilidad o bien de historia con profesores de historia o profesores de ciencias de la gestión. Mientras que los primeros se identifican con un campo profesional específico (el derecho o las tecnologías de la gestión) los otros se identifican (en la mayoría de los casos) con la docencia como profesión. Los profesores que no tienen una formación escolar (de grado o postgrado) en las ciencias de la educación, tienen un saber pedagógico desarrollado a través de la experiencia, primero como alumno y luego en la propia practica en las aulas ${ }^{9}$. Los docentes sin formación pedagógica en muchos casos ejercen otras actividades profesionales relacionadas con su titulo profesional y tienen a la enseñanza como actividad laboral complementaria, "vocacional", o como refugio cuando encuentran dificultades (transitorias o permanentes) para insertarse en el campo profesional delimitado por el titulo que poseen. Demás esta decir, que todavía hoy algunos sostienen que no existen pruebas contundentes y generalizadas para afirmar que el docente con formación pedagógica obtiene mejores resultados de aprendizaje que quienes no la tienen ${ }^{10}$.

La tensión entre contenido a transmitir y competencias pedagógicas y didácticas para hacerlo está particularmente presente en el caso del docente de enseñanza media. En efecto, este, a diferencia del maestro de primaria (que tiende a poner al niño en el centro de su atención) tradicionalmente colocó en

8 En varios países la figura del maestro único de grado que ocupaba una posición dominante en la relación con los alumnos (acompañado por el maestro de música y/o de gimnasia, entre otros) poco a poco se fue desarrollando una nueva división del trabajo pedagógico entre diversos maestros especialistas en las áreas curriculares básicas tales como las matemáticas, la lengua, las ciencias sociales, etc. Sin embargo existen indicios de que esta no es una tendencia necesariamente irreversible. Este es el caso de Italia, donde el gobierno actual (agosto 2008) está proponiendo un regreso a la figura del maestro único para los cuatro primeros años del nivel primario.

9 En muchos países de África los maestros empíricos (sin título docente) todavía predominan en el cuerpo docente ya que la necesidad de responder a la demanda de educación básica obligo a reclutar maestros entre la población que tiene pocos años de escolaridad formal. En estos casos lo que unifica a los docentes que trabajan en el sistema escolar es su trabajo y no su formación o pertenencia a una comunidad de graduados. Mientras que el médico o el abogado mantiene su identidad aún cuando no ejerza, en el caso de los maestros empíricos, solo se es docente si se desarrolla esta actividad.

10 En todo caso hay que recordar que la enseñanza es una actividad práctica que requiere habilidades específicas, muchas de las cuales solo "pueden ser transmitidas mediante el ejemplo y no mediante un precepto". "Las reglas del arte", como las teorías pedagógicas y los preceptos didácticos, por ejemplo, "pueden ser útiles, pero no determinan la práctica de un arte; son máximas que pueden servir como guía a un arte sólo si se pueden integrar en el conocimiento práctico del arte, y no pueden sustituir a ésta última" (POLANYI, 2006, p. 40). Integrar el aprendizaje de las reglas y conocimiento práctico es un dilema permanente de la formación de los docentes. 
primer lugar la disciplina que tenía la responsabilidad de enseñar. Desde este punto de vista, la perspectiva del profesor de secundaria es análoga a la del profesor universitario. Ambos se identifican con la disciplina que enseñan y ambos consideran que la responsabilidad de la adaptación en el proceso de enseñanza aprendizaje le corresponde al alumno ${ }^{11}$. Es él el que tiene que estar a la altura del conocimiento que ofrece el profesor. Es probable que la masificación e incluso la obligatoriedad de la enseñanza secundaria obliguen a redefinir esta perspectiva, volviendo más próximas las posiciones de maestro y la de profesor de enseñanza media. En la secundaria para todos, el profesor deberá poner más atención en las cualidades personales de los alumnos, hacerse responsable de su motivación y adaptar su enseñanza (los contenidos, las secuencias, los ritmos, la evaluación, etc.) a las particularidades de los aprendices ${ }^{12}$.

b) Otro factor de diferenciación tiene su origen en el tipo de institución donde se forman los profesores. En muchos países no existe un sistema institucional unificado de formación. En la Argentina, por ejemplo, los profesores se pueden formar en las Universidades o bien en Instituciones de educación superior no universitaria, específicamente creados para formar docentes. Aquí el debate se desarrolla en otros términos y suele oponer a quienes afirman que las universidades proveen una formación cultural (disciplinaria y pedagógica) excesivamente teórica y alejada de los problemas prácticos que los docentes tienen que resolver en su trabajo cotidiano en las aulas. En cambio, la formación en institutos especializados (Institutos de Formación Docente) es criticada por su carácter excesivamente escolar, es decir, apegado a las tradiciones y a la cultura escolar, lo cual les dificultaría actuar como agentes de cambio e innovación en los colegios donde desempeñarán su función. Lo cierto es que, por lo general, las universidades y los institutos de formación docente poseen no solo diversos programas curriculares, sino que ofrecen experiencias de formación diferente.

11 Por eso la pedagogía y la psicología de la educación son disciplinas mas desarrolladas y estructuradas en el nivel primario que en la educación media y superior.

12 Charles Peguy, citado por J.C. Passeron (2003) expresaba la opinión dominante de la época del secundario selectivo cuando afirmaba que "se puede denominar enseñanza superior a aquella que da lugar antes que nada a la consideración del conocimiento, y enseñanza primaria a aquella que, antes que nada, da lugar a la consideración de los alumnos". Cabe aclarar en las primeras décadas del siglo XX existían básicamente dos niveles de enseñanza, la primaria y la superior. La escuela secundaria formaba parte de la segunda. Y Peguy concluía que "El profesor (de educación superior) ... no va detrás de los alumnos. Ellos vienen a él [...] siguen su curso, lo escuchan para su beneficio, trabajan, si es necesario se preparan para escucharlo. Normalmente, él no tiene porque preocuparse por sus insuficiencias. Son ellos los que deben resolverlas. Hablando rigurosamente se puede decir que ellos han sido hechos para el curso, y que el curso no ha sido hecho para ellos, ya que ha sido hecho para el objeto del curso". 
Los institutos, en la mayoría de los casos presentan una mayor continuidad entre la escuela secundaria y la formación profesional, mientras que entre la Universidad y el colegio secundario (básico y superior) existe una mayor distancia ya que en la primera el estudiante es más autónomo y está más obligado a tomar decisiones personales en los estudios (debe decidir libremente que materias o cursos elegir, cuales hacer primero y cuales después, etc.). También la universidad ofrece experiencias formativas que van más allá del programa escolar (la militancia estudiantil, la sociabilidad, la invitación al distanciamiento crítico, etc.). En este caso tampoco existen evidencias contundentes que permitan elegir entre uno u otro modelo institucional. En realidad, la calidad de los profesores no depende tanto del modelo institucional donde estudiaron sino la calidad de los factores que configuran la oferta de formación (calidad del curriculum, de los docentes, de los apoyos didácticos, biblioteca, articulación entre teoría y prácticas de enseñanza, oportunidad de aprendizajes extracurriculares, etc.).

c) La docencia es una de las ocupaciones más masivas de las sociedades contemporáneas. Pese a lo que algunos suponían (y deseaban) las nuevas tecnologías de la información y la comunicación no han reemplazado al maestro, sino que constituyen nuevas herramientas para su trabajo en las aulas ${ }^{13}$. Ya vimos en un apartado anterior que los docentes se reclutan en todos los estratos sociales. Si bien su distribución en la estructura social no es homóloga a la distribución general de la población de un país, en general es cada vez más diversificada si se la mira desde una perspectiva histórica. En la etapa de la educación secundaria selectiva, los profesores de enseñanza en general provenían de las mismas capas sociales que sus alumnos. Hoy el acceso a la profesión se ha democratizado, ya que los profesores se reclutan en todos los estratos sociales. Es más, en ciertos contextos, pareciera ser que la docencia es un oficio atractivo únicamente para aquellos sectores medio bajos y bajos que aspiran a la movilidad social ascendente. A esta tendencia se opone la feminización del oficio. Los datos indican que dadas las condiciones de trabajo flexible que posee este oficio (trabajo por horas, medio tiempo, etc.) es particularmente apto para mujeres de sectores medio y medio alto, en la medida en que les ofrece un ámbito de realización personal fuera del hogar y las tareas tradicionalmente femeninas asociadas a la reproducción biológica y social de la población. De hecho el porcentaje de profesoras que se percibe como no siendo jefe de hogar es muy superior al de los profesores. En relación con lo anterior, en general las evidencias muestran que el porcentaje de profesoras que menos depende del salario docente (en rela-

13 Sin embargo no faltan y seguirán apareciendo voces que pregonan la sustitución lisa y llana del maestro y la escuela por la aplicación pedagógica de las nuevas tecnologías de la información y la comunicación. Un texto típico es el de Perelman (1995). 
ción con el total de los ingresos disponibles en sus hogares) es mayor que entre sus colegas varones. La mayor heterogeneidad social de los docentes a veces se asocia con representaciones distintas de la profesión. La vieja ideología del desinterés, la entrega y el sacrificio que muchas veces se asocia con la idea de vocación es más frecuente entre las profesoras que entre sus colegas varones, quienes por su posición en la familia están más inducidos a pensar el oficio como un trabajo o una profesion "de la cual" se vive.

d) El contexto social, institucional y territorial de los establecimientos donde trabajan los profesores también constituye un poderoso factor de diferenciación. En las primeras etapas del sistema educativo, cuando la enseñanza media estaba reservado a una minoría, las instituciones eran relativamente homogéneas ya que eran los alumnos quienes tenían la obligación de adaptarse ellas. Cuando el nivel medio se ha masificado las instituciones tienden a adoptar la "forma" de sus alumnos, invirtiéndose el tradicional "efecto de formación" (TENTI FANFANI, 2002). No es lo mismo trabajar en un colegio frecuentado predominantemente por alumnos de sectores populares que llegan por primera vez a este nivel educativo que trabajar en un colegio con alumnos de clase alta. El carácter socialmente homogéneo o mixto también marca una diferencia en las instituciones. Lo mismo puede decirse de la mayor o menor diversidad étnica y cultural de los alumnos. En muchos casos las instituciones quedan marcadas por el tipo de público que a ellas asiste. También el territorio donde están situadas las instituciones determinan el trabajo de los docentes. En el caso de la enseñanza primaria un docente de escuelas rurales vive una experiencia y desarrolla una identidad especifica que lo diferencia de su colega que trabaja en el centro de una gran ciudad. En este mismo sentido, el carácter estatal o no estatal de un colegio también puede determinar una identidad de los agentes que lo frecuentan (sean estos alumnos o profesores). Y entre los colegios privados no es lo mismo uno que persigue finalidad de lucro de otro cuya razón fundamental de ser consiste en reproducir una determinada tradición religiosa o étnica. Es sabido que en casi todas las sociedades capitalistas las diferencias sociales y culturales tienden a situarse en determinados espacios territoriales. Las instituciones escolares están situadas en el territorio y por lo tanto tienden a ser cada vez más homogéneas desde este punto de vista. Esta tendencia contribuye a reforzar la diferenciación del cuerpo de los profesores, sean estos de nivel primario o de secundario. En muchos casos estas diferencias se expresan en el campo sindical que representa a los docentes. En muchos países existen sindicatos de docentes del sector privado, y sindicatos que representan a quienes trabajan en el sector público, dado que ambos contextos institucionales tienen sus regulaciones laborales especificas. 
e) Por último, hay que agregar otro factor de diferenciación importante. Este tiene que ver con el modelo de gestión de los sistemas educativos públicos. Estos dependen en gran medida del tipo de división del trabajo entre los distintos niveles del gobierno: nacional, regional, provincial y municipal. Existen dos tradiciones básicas: la unitaria y la federal. El Estado-nación argentino por ejemplo, pese a su configuración política federal desplegó una fuerte burocracia educativa nacional, en especial en la enseñanza secundaria. En este marco institucional el trabajo y la identidad docente tuvo una fuerte impronta nacional que contribuía a su homogeneidad como cuerpo. Las mismas políticas, las mismas regulaciones, un mismo sistema de formación (Las Escuelas Normales Nacionales) y condiciones de trabajo conformaron un conjunto de principios estructuradotes del oficio docente. Los procesos de descentralización de la educación primaria primero (1978) y secundaria y Normal después (1992) implicaron una fragmentación de las políticas y la gestión de la docencia. La consecuencia fue una diversificación de las condiciones de formación, trabajo y remuneración de los profesores argentinos que alentó las tendencias a la diversificación del cuerpo docente en función de las jurisdicciones donde se forman y trabajan. Este proceso de expresó en una fragmentación de la conciencia colectiva de los trabajadores de la educación en la medida en que se vieron obligados a negociar sus condiciones de trabajo con cada uno de los gobiernos provinciales. De este modo, se debilitaron también los sindicatos nacionales docentes como representantes de los intereses del colectivo de trabajadores de la educación nacional.

A modo de reflexión final, es preciso observar que esta tendencia a la fragmentación del colectivo docente, alentada por estos y otros factores dificulta grandemente la constitución de dispositivos de representación. Estos, por naturaleza, tienden a darle una sola voz a los representados (fortaleciendo así su capacidad de negociación y lucha ante el Estado empleador). Pero esta tarea es cada vez más dificultosa pues obliga a la articulación de intereses y situaciones extremadamente diversos. La pluralidad de expresiones sindicales docentes (por territorios, niveles, orientaciones, especialidades, modalidades, etc.) es un indicador de esta dificultad de representación.

Frente a esta diversidad creciente del trabajo y la identidad docente es posible plantear una especie de tendencia a la personalización de la construcción del oficio (lo que hay que hacer y como hacerlo). La misma sería casi una aventura personal cuyo desenlace es una función de la relación entre ciertas características ligadas a la trayectoria (social, de formación, experiencia profesional, etc.) y el contexto de ejercicio del trabajo docente (el nivel educativo, características de los establecimientos escolares, de los alumnos, etc.). 


\section{Los docentes y los nuevos alumnos}

Ya dijimos antes que el docente de media está situado entre dos mundos. Uno es el mundo de los adultos y de la escuela secundaria tradicional, con su programa escolar, sus dispositivos pedagógicos, su lógica selectiva etc. y otro el mundo de los adolescentes de hoy.

La percepción que los profesores (adultos) tienen acerca de los valores de los jóvenes nos ofrece una oportunidad de analizar algunas dimensiones de la relación compleja entre la cultura de los docentes y la de sus estudiantes.

El programa de investigación sobre profesionalización docente en América Latina (IIPE/UNESCO, 2000) incluyó un indicador que buscaba conocer cuáles eran las representaciones de los docentes acerca de la presencia de ciertos valores en la juventud actual. En general, los resultados obtenidos (Cuadro 7 del Anexo) indican una actitud generalizada de pesimismo respecto de las nuevas generaciones en términos de sus valores ético-morales. Las opiniones de maestros y profesores de enseñanza media son sorprendentemente homogéneas. En efecto la mayoría es consideró que estos valores sociales deseables "se debilitan". Sólo cuando se trata de apreciar la vigencia del "amor a la libertad" y el "cuidado de la naturaleza”, un tercio de los docentes consideró que se trata de valores que "se fortalecen". Sin embargo, una contundente mayoría de tres cuartos o más docentes creen que en la juventud actual (la mayoría...) se debilitan valores tan estratégicos como "el compromiso social", "la responsabilidad", "el sentido de familia", "la seriedad", "el sentido del deber", "el respeto a los mayores" y la disposición al esfuerzo".

Por otro lado, más de la mitad de los adultos docentes consideran que se debilitan valores tales como "la espiritualidad", "la honestidad", "el sentido de justicia" y "la tolerancia".

Este cuadro extremadamente crítico y pesimista respecto de las tendencias éticas de la juventud actual son por lo menos preocupantes y están delatando una sensación de decadencia y malestar moral que seguramente tiene sus efectos sobre las mismas relaciones que los docentes mantienen con las nuevas generaciones en las aulas de las instituciones escolares sobre las cuales es preciso reflexionar.

Con el conjunto de las respuestas aportadas por los docentes a la pregunta relacionada con los valores de los jóvenes (cuyos resultados generales se presentan en el Cuadro 7 del Anexo) podemos construir un índice de optimismo/ pesimismo en relación con los valores de los jóvenes (Cuadro 8 del Anexo). En verdad, lo que el índice sumativo mide es el grado (alto Medio Bajo) de la 
actitud en general negativa de los docentes respecto de la ética privada y pública de los jóvenes actuales. Este índice se asocia con ciertas características. Los datos del cuadro 8 del Anexo muestran su comportamiento en las distintas regiones del país. La actitud en general negativa de los docentes frente a los comportamientos y valores de la juventud actual es mucho más fuerte en tres regiones: Noreste, Noroeste y Cuyo. Esta visión marcadamente crítica es menos marcada en el ámbito metropolitano de Buenos Aires. En este caso se observa, una vez más, una relación sistemática entre orientaciones de valor de los docentes y determinados grados de desarrollo económico y social de los diversos territorios del país.

Tampoco la edad de los docentes o su condición económico social (objetiva y percibida) aparece muy asociada con sus valoraciones. Sólo se observa una mayor presencia de la visión crítica en los docentes del sector público en relación con los privados (Cuadro 9), pero pese a ello, todo pareciera indicar la existencia de un mismo modo (negativo) de valorar a los jóvenes por parte de los docentes como una categoría social/profesional. Sólo aparecen como dignas de análisis y consideración, las variaciones en el territorio nacional.

Para entender mejor el sentido de esta actitud crítica, es preciso tener en cuenta, entre otras cosas, que la lista de valores seleccionados no agota el conjunto de valores posibles y presentes en la sociedad. En verdad, la lista remite a valores de los adultos, que en muchos casos deja afuera valores propios de las nuevas generaciones tales como la "autorrealización", la "felicidad", "el espíritu de aventura", "la comunicación y el diálogo con los semejantes", la "expresividad", "la sinceridad", la "autenticidad", etc. Es probable que la juventud sea portadora de nuevos valores y definiciones de lo que es una "buena vida", que en cierta medida se diferencian de los que hoy son adultos. No es un detalle menor el hecho de que según los docentes sea "la libertad" un valor que ellos ven que se fortalece entre las nuevas generaciones, pero es probable que el sentido que dan a "la libertad de los jóvenes", en muchos casos no sea positivo, sino que se asocie con la ausencia de límites, la falta de respeto a la autoridad, los mayores, los ancianos y también a los docentes.

Esta representación extremadamente crítica y negativa de los adultos docentes respecto de los jóvenes (que probablemente es compartida por la mayoría de la población adulta de nuestra sociedad) necesite ser objeto de reflexión más profunda en la medida en que seguramente están detrás de una serie de prejuicios y expectativas que pueden constituir un fuerte obstáculo a la contribución que se espera de la educación escolar en el campo de la propia formación ética y cognitiva de las nuevas generaciones.

Esta visión pesimista de los adultos de alguna manera "se transmite" a los alumnos de modos muy diversos, unos explícitos y otros implícitos, pero por 
ello no menos eficaces. Cada uno tiende a parecerse a la imagen que los otros tienen de nosotros. Esta especie de "efecto espejo" (por lo general no controlado por los agentes implicados) es tanto más eficaz cuando quien lo produce tiene cierto poder o cierta autoridad, como es el caso de los profesores. Por lo tanto, es probable que esta imagen crítica de alguna manera interfiera en la relación de comunicación entre profesores y alumnos y de alguna manera constituya una fuente de dificultad en la construcción de la autoridad pedagógica y del orden democrático en las instituciones.

Esta visión crítica y negativa de los docentes acerca de los valores de "la juventud actual", de alguna manera se asocia con otra idea muy generalizada: la de que a los alumnos de hoy "no les interesa nada". De esta manera, "el interés por el estudio" (o por la cultura escolar, el programa y/o contenidos escolares, etc.) se constituye en una especie de ausencia que los docentes señalan también como una fuente de dificultad en la enseñanza que explica gran parte de los éxitos y fracasos en los procesos de aprendizaje.

a) El déficit de interés y motivación

Muchas veces no se sacan todas las consecuencias del hecho de que la enseñanza y el aprendizaje es un proceso de coproducción, donde es tan importante "lo que pone" el profesor, como "lo que pone el alumno". La relación pedagógica, para ser efectiva, requiere de un trabajo de ambas partes. Pero no se trata de un trabajo cualquiera. No es lo mismo enseñar y aprender que apretar tornillos en una cadena de montaje. Uno puede realizar este trabajo mecánico "pensando en otras cosa" mientras realiza ciertas operaciones. En cambio, para que el aprendizaje tenga lugar, los agentes de la relación pedagógica tienen que encontrar sentido en lo que hacen, deben estar motivados y en el mejor de los casos deben estar apasionados por la enseñanza y el aprendizaje. En último término la crisis de la escuela secundaria se manifiesta por un déficit de sentido para los que "trabajan" en el aula ${ }^{14}$. Esta ausencia de interés y motivación de unos retroalimenta recíprocamente la de los otros, lo cual vuelve a la situación aún más compleja.

En demasiadas ocasiones, la experiencia escolar, en especial la de los hijos de las familias tradicionalmente excluidas del secundario, no tiene mucho sentido para ellos. Esta es una realidad que no es exclusiva de la Argentina. François Dubet escribe que en Francia, los adolescentes y jóvenes que frecuentan la

14 Hace quince años publiqué "La esuela vacía" (Losada, Buenos Aires, primera edición de 1993). Con ese título pretendía sintetizar la crisis de la escuela contemporánea como un déficit de sentido, desigual por cierto, para una proporción significativa de docentes y estudiantes de la educación básica. El vacío del que habla el título tiene que ver con la pérdida de centralidad del aprendizaje de conocimientos socialmente significativos. 
secundaria superior "no son ni 'herederos' programados apasionarse por sus estudios ni becarios convencidos de la utilidad de sus estudios y de sus esfuerzos. Casi todos también se sienten empujados hacia una vida juvenil intensa que los aleja de un compromiso que se suponía total con sus estudios" (DUBET, 2007, p. 53). Este deterioro del interés y de la propensión al esfuerzo escolar tiene dos fuentes de alimentación: por una parte los diplomas de la enseñanza media ya no aseguran los premios y recompensas que solían garantizar en el pasado y por la otra, los estudiantes, en tanto que jóvenes tienen otras esferas sociales (los espacios, instituciones y consumos propios de los "jóvenes") que antes no existían.

El déficit de interés por aprender lo que la secundaria les propone a los alumnos de hoy es una fuente de desmoralización de los docentes. Ellos perciben que lo que tienen para "transmitir" (y deben transmitir, según el programa escolar) muchas veces está lejos de las necesidades y pasiones de las nuevas generaciones, las cuales invierten sus esfuerzos en otros campos de la vida social (el mundo del deporte, la música, los amigos, el esparcimiento, etc.). El docente de media se siente desvalorizado por sus alumnos y por lo tanto su autoridad pedagógica comienza a verse seriamente comprometida. Un profesor al que no se le cree, al que no se lo respeta se convierte en un profesor ineficaz para dejar huellas en la subjetividad de sus alumnos.

Aquí describimos una situación típica, que no se presenta con la misma intensidad en el ancho, diversificado y jerarquizado mundo de la enseñanza media. Sin embargo, marca una tendencia preocupante, en especial cuando se trata de las instituciones que atienden a alumnos de sectores sociales socialmente excluidos. En estas situaciones límites, estudiantes y profesores van al colegio, pero su experiencia es totalmente insatisfactoria, cuando no es fuente de conflictos y padecimientos más o menos sistemáticos.

"A los alumnos de hoy no les interesa nada" suelen decir, a modo de queja, muchos docentes de enseñanza media. En verdad lo que están diciendo con esta constatación tan radical, es que no les interesa lo que ellos les están enseñando, que no es otra cosa que lo que saben enseñar. Cómo no sentir entonces una sensación de impotencia y malestar? Una vez más es preciso constatar que el profesor en el aula no trabaja "solo". Este, al igual que el actor en el teatro, el sacerdote en la iglesia y el político en el mitin, para hacer bien su trabajo, necesita de la cooperación de su público.

Por eso los docentes deben ser antes que nada, motivadores, generadores de la demanda de conocimiento en sus alumnos. Dados los equilibrios de poder existentes entre las generaciones (no nos olvidemos que hoy los alumnos tienen derechos) no se pueden dar por descontados ni el interés por aprender, ni el respeto al profesor. Ambos requisitos necesarios para que el aprendizaje tenga 
lugar deben ser cada vez más un objetivo del esfuerzo personal del docente. Ambos son desafíos novedosos para cuya resolución no es suficiente reclamar el retorno a los viejos dispositivos disciplinarios.

b) La crisis de la autoridad pedagógica

Otro factor que viene a poner en crisis los viejos modos de hacer las cosas de los docentes se origina en los cambios en los equilibrios de poder entre los niños y jóvenes y los adultos. La edad siempre fue un principio estructurador de las relaciones de dominación en todas las sociedades y durante la segunda mitad del siglo XIX, cuando se sentaron las bases de las instituciones educativas capitalistas, la relación de poder entre las generaciones era mucho más asimétricas que en la actualidad. El mundo de los adultos (los padres, los maestros, los directivos, los "celadores", etc.) prácticamente monopolizaba el poder en las instituciones. Los alumnos tenían más deberes y responsabilidades que derechos y capacidades. Los reglamentos y dispositivos disciplinarios de los establecimientos escolares constituyen una objetivación del poder omnipotente que tenían los adultos sobre las nuevas generaciones.

Por una serie de razones estructurales que se despliegan en el tiempo largo de la historia, el equilibrio de poder entre las generaciones ha sufrido cambios sustanciales (ELIAS, 1997). En la actualidad, aunque las relaciones intergeneracionales siguen siendo asimétricas y a favor de los "más grandes", esta asimetría se ha modificado profundamente en beneficio de las nuevas generaciones. Hoy los niños y adolescentes son considerados como sujetos de derecho. No sólo tienen deberes y responsabilidades vis à vis de los mayores, sino que se les reconoce capacidades y derechos.

La Convención Internacional de los derechos del niño su incorporación prácticamente universal (aun falta una firma significativa, la de los EEUU) es un indicador del grado de institucionalización alcanzado por estas nuevas relaciones de poder intergeneracional.

Las instituciones educativas tienen que tomar nota de esta realidad y transformar sus dispositivos, en especial aquellos que regulan las relaciones de autoridad entre profesores, directivos y alumnos, las que organizan el orden y la disciplina y aquellas que estructuran los procesos de toma de decisión.

Habrá que reconocer que los adolescentes y jóvenes tienen derechos específicos (a la identidad, a expresar sus opiniones, a acceder a la información, a participar en la definición y aplicación de las reglas que organizan la convivencia, a participar en la toma de decisiones, etc.) y habrá que diseñar los mecanismos institucionales que garanticen su ejercicio (reglamentos, participación en cuerpos colegiados, recursos financieros, de tiempo y lugar, competencias, etc.) (TENTI FANFANI, 1999). 
El reconocimiento de derechos a los adolescentes aunado a la erosión de las instituciones escolares (producto de la masificación con subfinanciamiento y a la pérdida de monopolio en el campo de las agencias de imposición de significados) están en el origen de la crisis en la autoridad pedagógica como un efecto de institución. En las condiciones actuales, los agentes pedagógicos (maestros, directivos, expertos, etc.) no tienen garantizada la escucha, el respeto y el reconocimiento de los jóvenes. Pero la autoridad pedagógica, entendida como reconocimiento y legitimidad sigue siendo una condición estructural necesaria de la eficacia de toda acción pedagógica. El problema es que hoy el maestro tiene que construir su propia legitimidad entre los jóvenes y adolescentes. Para ello debe recurrir a otras técnicas y dispositivos de seducción. Trabajar con adolescentes requiere una nueva profesionalidad que es preciso definir y construir.

\section{Nuevas condiciones objetivas de trabajo y competencias de los profesores de enseñanza media}

Han cambiado los alumnos y han cambiado las condiciones sociales que estructuran la construcción social de la adolescencia y la juventud. La familia de ayer no tiene mucho que ver con la de hoy, las nuevas generaciones constituyen agentes extremadamente diversificados pero identificados cada vez más con su condición de edad. Los adolescentes y jóvenes se van constituyendo en sujetos de derecho, son productores y consumidores intensivos de productos culturales que le son propios y que los distinguen de otras clases de edad. Hasta cierto punto, la condición juvenil se convierte en arquetipo de la condición humana deseable. Como "clase de edad" tiende a autonomizarse de los mayores y al mismo tiempo tiende a la autosuficiencia, perdiendo fuerza la necesidad de establecer vínculos con el pasado que los antecedió. El mundo de los adultos tiende a serles ajeno y todos los objetos (culturales, materiales, etc.) que le son propios tienden a desvalorizarse a los ojos de las nuevas generaciones. En consecuencia, estos tienen cada vez más dificultades para erigirse en agentes autorizados para transmitir algo valioso (un cultura, un saber, una moral, una estética, etc.).

Estos cambios necesitan ser comprendidos en cuanto a la lógica de su génesis y desarrollo, para poder valorar lo que es progresivo en ellos y al mismo tiempo para determinar qué es lo que hay de progresivo en términos de desarrollo de una sociedad más libre, más rica y más humana y solidaria. Un caso ejemplar lo constituye el tema de los derechos de los niños. No es posible no 
advertir lo que hay de liberador en este movimiento universal que va del niño cosa, objeto del poder de los adultos al niño sujeto con derecho a la autonomía y a la construcción de una vida que le es propia y a la que tiene derecho. Sin embargo, la ruptura total entre las generaciones no es positiva cuando pone en peligro la idea misma de sociedad como totalidad de agentes interdependientes, que tiene una historia que nos trasciende y que nos hace ser lo que somos, al mismo tiempo que nos permite ir más allá de los determinismos del pasado.

Los profesores, en tanto representantes significativos del mundo adulto deben cumplir con una función estratégica fundamental: deben ser agentes que colaboran con la apropiación de una herencia cultural por parte de las nuevas generaciones, que sólo en forma ilusoria pueden creer que pueden empezar de cero desconociendo el valor de "las cosas del pasado". Toda la cultura, la ciencia y la tecnología moderna hunde sus raíces en el pasado y encuentra en él sus propias condiciones de desarrollo futuro. Salvo dios, nadie es capaz de crear a partir de la nada. Sobran los ejemplos para demostrar que en el campo de la cultura los más creativos, innovadores y revolucionarios son quienes más se han apropiado de los logros del pasado. El ignorante es estéril, aún cuando tenga pretensiones y ambiciones grandiosas.

Para que el profesor desarrolle efectivamente una nueva profesionalidad y esté en condiciones de cambiar el modo de hacer las cosas se requiere una reforma institucional. La misma debe partir de una definición clara del sentido y funciones de la enseñanza media en la Argentina contemporánea. Para ello habrá que ir más allá de los consensos fáciles y engañosos. Es probable que un verdadero debate sobre la cuestión permita la emergencia de distintas versiones acerca de la cuestión, incluso opuestas o contrapuestas ${ }^{15}$. Del debate y la argumentación democrática debe surgir un consenso mayoritario que permita orientar

15 No es fácil definir qué es lo que tiene que saber todo ciudadano para "ser alguien en la sociedad". En efecto, el viejo secundario, como antesala de la universidad, privilegiaba una definición del conocimiento estrictamente disciplinaria. Pero si el secundario es para todos, quizás lo debiera preocuparnos e la definición de una "cultura común" entendida como condición básica para la autonomía, la ciudadanía y el aprendizaje permanente. Al respecto, en otros países que tienden a la universalización de la enseñanza media se ponen el mismo problema cuando observan que durante los últimos años donde "se democratiza el acceso" al secundario (se vuelve obligatorio para todos) se tiende a la "elitización de los contenidos del programa escolar". En otras palabras, las disciplinas se vuelven más abstractas y por lo tanto menos útiles para resolver problemas vitales de las nuevas generaciones (DE CLOSETS, 1996). La misma preocupación aparece en un ensayo reciente de un lingüista que denuncia la tendencia "teorizar" la enseñanza de la lengua y la literatura (enseñanza de las teorías lingüísticas, de definiciones, taxonomías, conceptos, etc.) poniendo en segundo lugar el objetivo de desarrollar en los jóvenes el placer de la lectura y la apropiación de todo el capital de sabiduría que contiene la literatura clásica y contemporánea (TODOROV, 2007). 
el sistema normativo de un nuevo colegio secundario. Entre las primeras cosas a definir, luego del sentido, es el conocimiento o conjunto de aprendizajes que todos los adolescentes deben desarrollar y las condiciones sociales y pedagógicas necesarias para lograrlo. Lo mismo sucederá con los recursos (humanos, financieros, organizacionales, de infraestructura, tecnológicos, etc.) necesarios para hacer realidad la educación secundaria para todos.

Una vez definido el sentido, contenido, modelo pedagógico y nuevo marco institucional (que incluye las condiciones de trabajo del docente y el diseño de una nueva organización escolar) hay que definir las condiciones subjetivas de la profesionalidad docente. La misma deberá responder a la pregunta de qué es lo que debe saber el docente (en términos de contenidos culturales y estrategias pedagógicas y didácticas). Pero también habrá que definir el conocimiento que necesita el docente para interactuar con sus alumnos (habrá que conocer al alumno no sólo desde el punto de vista psicológico sino también social y cultural) y para entender la relación compleja entre dimensiones relevantes de la sociedad y el mundo de la escuela (la lógica de la producción y el mundo del trabajo, los sistemas de producción y difusión de la cultura, la estructura social, la estructura y dinámica de la familia, los avatares de la construcción y profundización de la democracia, la relación entre la identidad nacional y la interdependencia con otros estados nacionales en el contexto de la globalización y extensión de los lazos de interdependencia entre las naciones (a nivel regional y mundial), entre otros contenidos culturales que contribuyen a darle sentido a lo que hace y produce la educación escolar.

Pero en la "mochila de recursos" cognitivos del nuevo profesor no deberán faltar una serie de componentes de tipo no estrictamente cognitivo. Nos referimos a las características de personalidad y ético morales que son necesarias en todo trabajo que consiste en un servicio de persona a persona, donde la relación con el otro tiene una importancia estratégica fundamental. Dijimos antes que el profesional democrático debe proponerse como primera prioridad desarrollar en los alumnos la motivación, el interés e incluso la pasión por el conocimiento. Que este es un requisito fundamental para el aprendizaje que en las condiciones sociales actuales no es posible dar por descontado. Para que el maestro sea un agente movilizador del interés de los alumnos es preciso que posea una serie de cualidades y habilidades que van más allá del plano de lo estrictamente disciplinario y pedagógico. Aquí nos referimos a capacidades que hay que movilizar para relacionarse con los otros (este caso, los colegas, los aprendices, sus familias, la comunidad, etc.) y que remiten a actitudes, valores y predisposiciones tales como la confianza, la generosidad, el respeto por el derecho de los otros, el reconocimiento de su identidad, el cuidado e interés por su bienestar presente y futuro, etc.) que de alguna manera es preciso desarrollar 
mediante estrategias adecuadas y que constituyen un desafío particular para la pedagogía de la formación docente.

Cabe destacar que sólo la posesión de un nuevo capital cultural incorporado en los profesionales de la educación podrá garantizar la producción de la necesaria autoridad que se necesita para obtener el reconocimiento y la cooperación de los propios alumnos en su propio proceso de aprendizaje. La autoridad, que antes era el resultado casi automático de un acto de delegación institucional (se reconocía y obedecía al profesor, simplemente porque tenía un nombramiento y ocupaba el lugar de la cátedra) ahora sigue siendo tan necesaria como antes, pero ahora es cada vez más el resultado de una producción propia por parte del profesor. Y para ello hay que contar con los recursos necesarios para producirla $\mathrm{y}$ reproducirla en forma permanente.

Por último, y para evitar las visiones parciales e incompletas, hay que recordar que lo que se busca con la nueva profesionalidad de los profesores es cambiar las prácticas, es decir, lo que efectivamente sucede en las aulas. Para ello se necesitan políticas integrales ya que nada se conseguiría con reformar y enriquecer las instituciones (instalando el profesor full time por cargo, actualizando y flexibilizando el currículo y el sistema de evaluación, aumentando el tiempo de clase, aumentando el salario docente, mejorando la carrera de los profesores, etc.) sin modificar profundamente el sistema de formación de los docentes. Lo anterior sería tan estéril como pretender jerarquizar y actualizar la formación integral de los profesores manteniendo intactos los recursos institucionales, los sistemas de remuneración, carrera, etc.). Una sana sociología enseña que para cambiar las prácticas hay que cambiar en forma armónica y contemporánea tanto las condiciones estructurales donde ésta se desenvuelve, como el sistema de competencias, conocimientos, actitudes y predisposiciones de los agentes implicados. Los que absolutizan las capacidades de los sujetos apuestan exclusivamente a la concientización y a la formación de los docentes. Los fundamentalistas de la estructura están convencidos que para cambiar las prácticas basta con modificar las reglas y recursos que la estructuran. Una visión integral y respetuosa de la complejidad de las prácticas humanas aconseja intervenir sobre los agentes y sobre las estructuras al mismo tiempo. Es un camino más difícil, por cierto, pero es el único que ofrece una posibilidad de implementar políticas de cambio que vayan más allá de las buenas intenciones que habitan en los discursos de tantos políticos e intelectuales de la educación. 


\section{El profesor como artista ejecutante y su evaluación}

Pensar al trabajo docente como una "performance" puede ser de utilidad cuando se quiere comprender su especificidad. Con Paolo Virno (2003) uno podría preguntarse qué tienen en común "el pianista que nos deleita, el bailarín experimentado, el orador persuasivo, el profesor que nunca aburre o el sacerdote que da sermones sugestivos" (p. 45); la respuesta es: la virtud, entendida como el conjunto de capacidades de los artistas ejecutantes. La docencia, entonces es un trabajo de virtuosos y esto al menos por dos razones:

a) es una actividad que se cumple y tiene el propio fin en si misma y

b) es una actividad que exige la presencia y cooperación de otros, es decir, que necesita de un público.

Por lo tanto es un trabajo sin obra, sin producto: es una performance. Una buena clase no tiene producto inmediato. Según Virno, a falta de productos el virtuoso tiene testigos. La virtud (la calidad del docente) esta en la ejecución y en la actuación y no en el producto.

Por lo tanto la enseñanza es una praxis, es decir, una acción que tiene su fin en sí misma, que se manifiesta en su desarrollo. Desde este punto de vista la praxis del docente es como la conducta ética y política y se diferencia de una practica productiva que termina en la elaboración de un producto determinado y separado del trabajo. En este caso la calidad de la ejecución esta en el producto (es improbable un zapatero que trabaja bien pero produce zapatos defectuosos).

El maestro hace un trabajo donde el producto es inseparable del acto de producir. Es una actividad que se cumple en si misma, sin objetivarse en un resultado inmediato y evaluable.

¿Y cuál es la capacidad (o "competencia" ... si seguimos los dictados de la moda) que distingue a los ejecutantes virtuosos? La capacidad comunicativa, responde Virno. La comunicación se convierte en el contenido central del trabajo. Por eso el público (en este caso los alumnos y sus familias) es el evaluador primario e inapelable del trabajo del docente. Solo ellos están en condiciones de formular un juicio de valor, porque ellos "están allí" donde el maestro ejecuta su acción pedagógica. Virno se pregunta también "cómo se hace para evaluar a un cura, a un experto en publicidad, a un experto en relaciones publicas? Como se hace para calcular la cantidad de fe, de deseo de posesión, de simpatía que ellos son capaces de crear?". La misma pregunta vale para los profesores: cómo se hace para medir y evaluar la cantidad de pasión, de curiosidad, de creatividad, 
de sentido crítico en relación con el conocimiento y la cultura que es capaz de producir un maestro en sus estudiantes?

Dijimos antes que el docente de hoy debe ser antes que nada un generador de motivación, interés y pasión por el conocimiento. También debe crear y recrear permanentemente las condiciones de su propia autoridad y reconocimiento. Y qué recursos hay que poseer y emplear para ejecutar esta función y lograr estos estados? Es probable que ellos mismos deban poseer estas cualidades en relación con la cultura y el conocimiento para poder suscitarlos en sus estudiantes. Para ello necesitan tener competencias expresivas, saber, imaginación, capacidad comunicativa. Debe saber movilizar emociones y sentimientos y para ello debe invertir el mismo estas cualidades de su personalidad (MARCHESI, 2008).

De esta peculiaridad del trabajo del docente se derivan una serie de consecuencias al momento de decidir qué estrategias emplear para medir la calidad de su trabajo. Esta es una preocupación propia del gestor de la educación. No es una preocupación de las organizaciones representativas de los trabajadores de la educación, sino de los políticos y administradores de los sistemas educativos contemporáneos. En muchos casos ellos tienden a considerar al trabajo docente como cualquier trabajo productivo y creen que el maestro produce un producto: el individuo educado. El producto del trabajo del profesor sería el aprendizaje de los alumnos. Pero aunque uno acuerde con esta proposición, debe tener en cuenta al menos tres cuestiones básicas:

a) La primera tiene que ver con el hecho de que es por lo menos difícil pensar la relación entre el trabajo de un docente singular y el aprendizaje de sus alumnos. Por lo general el trabajo de un maestro es contemporáneo con el trabajo de otros maestros. ¿Cómo hacer para distinguir el efecto específico de uno en relación con el de los otros?

b) La segunda es que el aprendizaje no depende solo de la performance de los profesores. Se sabe casi desde siempre que lo que un alumno aprende depende de otros factores que los profesores, por lo general, no siempre están en condiciones de controlar. El efecto de los llamados factores sociales no escolares (capital cultural familiar, aprendizaje extraescolar, etc.) son tan (y a veces más importantes) que los propiamente pedagógicos. ¿Cómo separar entonces lo que se puede imputar a la virtud de los docentes y lo que se debe a otras experiencias extraescolares? Las técnicas estadísticas que se utilizan con mayor frecuencia no permiten medir en términos de "causalidad estructural" (o el efecto de interdependencia) las complejas relaciones entre las "variables de la escuela" y las "variables del alumno". 
c) La tercera cuestión a tener en cuenta en la evaluación es que muchas veces los aprendizajes desarrollados en la escuela solo se manifiestan y valorizan en un momento diferido del tiempo. Hay cosas que se aprenden en el presente y que solo se valoran muchos años después, cuando el aprendiz se inserta en determinados campos de actividad. ¿Cómo distinguir los aprendizajes efímeros de aquellos realmente valiosos, es decir, permanentes? La durabilidad de los aprendizajes debe ser tenida en cuenta al momento de evaluar su calidad. Y esto solo puede hacerse post escuela.

En tanto servicio personal que se ejerce con otros y "sobre otros" la enseñanza "es un trabajo difícilmente objetivable, un trabajo cuya 'producción' se mide mal" (DUBET, 2002, p. 305). Pero además, las evaluaciones que se hacen del trabajo del docente, por más detalladas y exhaustivas que pretendan ser, siempre dejan de lado algún aspecto que es juzgado esencial por los propios protagonistas, los cuales difícilmente se reconozcan en esas evaluaciones. Por lo general esas cosas que no se evalúan tienen que ver con las relaciones cara a cara con los alumnos, con las familias, con el director y los colegas, aspectos que sin duda constituyen un capítulo fundamental de su trabajo. En la cuestión relacional el maestro pone mucho de sí, pone su cuerpo, sus sentimientos y emociones, es decir mucho más que el conocimiento de competencias, técnicas o procedimientos aprendidos. En realidad, cuando se habla de virtuosismo del docente, se hace referencia a estas cualidades que se ponen en juego en la relación con los otros para obtener credibilidad, confianza, para evitar o resolver conflictos, evitar tensiones, etc.

Según esta perspectiva hay que distinguir dos dimensiones en el trabajo docente. Una tiene que ver con el contenido crítico y ético del trabajo; la otra se desprende del contexto organizacional donde el maestro actúa. No hay que olvidar que la performance docente no se despliega en el vacío sino en un contexto organizacional, predominantemente de tipo burocrático, es decir, regulado y jerárquico. Según Dubet, "la yuxtaposición de esta lógica de organización y de un trabajo crítico fuertemente subjetivo participa de una representación de la vida social en la cual los temas individuales y morales parecen separarse de aquellos de la actividad organizada". La mayoría de los maestros, "están tentados a oponer el calor y la singularidad de su experiencia en el trabajo a la objetividad anónima de las organizaciones que enmarcan su actividad" (DUBET, 2002, p. 306).

Si el trabajo del docente es estructuralmente complejo de "medir", más difícil y cuestionable es hacerlo en un momento determinado del tiempo y usando solo un instrumento de "medición". En todo caso, los aprendizajes de los alumnos al finalizar un año escolar pueden servir como un indicador, extremadamente incompleto, para medir la virtud del docente ejecutante. Es probable 
que haya que diversificar la evaluación del producto al mismo tiempo que buscar estrategias que tomen en cuenta la calidad de la ejecución. Aquí nuevamente hay que decidir quienes están en condiciones de opinar sobre la misma. Lo que es cierto es que en este caso, los alumnos y sus familias tienen ventajas ciertas con respecto a los gestores y políticos de la educación.

Un indicador de la complejidad que plantea la evaluación de los docentes es el hecho de que en casi todas partes este es un tema extremadamente conflictivo y acerca del cual existe poco consenso. Incluso en muchos países, que se destacan por la calidad de sus sistemas educativos (Finlandia es un caso ejemplar) incluso no existe ninguna evaluación formal de los docentes.

En síntesis, los alumnos, los propios docentes y las familias (en el caso de los maestros de primaria) lo general no se equivocan cuando distinguen a un buen profesor de un mal profesor. Sin embargo esta "evaluación", por ser informal, produce un capital de prestigio que, al no estar objetivado e institucionalizado no produce consecuencias mayores sobre la carrera de los docentes (asignación de funciones jerárquicas, salarios, etc.).

Cabe destacar que el problema se plantea cuando los sistemas educativos, al privilegiar la expansión de la escolarización sin invertir lo necesario en la formación de los docentes ni en salarios y condiciones de trabajo han contribuido primero a la decadencia del oficio para luego denunciar "la baja calidad de la docencia". Quizás una adecuada comprensión del proceso que llevó a esta situación permitiría ver que en muchos casos los profesores también fueron victimas de un proceso que en gran parte los trasciende. Si se parte de esta hipótesis, mas que gastar en evaluar a los docentes en ejercicio (para "condenarlos" como en el Perú actual) habría que mejorar sustantivamente la formación de los docentes y sus condiciones de trabajo y remuneración en vez que gastar en evaluaciones que tienen por objeto condenar a las victimas ante la sociedad, ocultando así las responsabilidades históricas de la clase política en la degradación del oficio de docente. Pero más allá de esta discusión es evidente que en la mayoría de los países existe una distancia entre la realidad del trabajo cotidiano de los docentes en las aulas y el discurso oficial de las políticas educativas que formalmente busca adaptar la educación a las nuevas condiciones y exigencias, muchas veces contradictorias, que se generan en las dimensiones económicas, sociales y culturales de la sociedad contemporánea. 


\section{BIBLIOGRAFÍA}

CAVALLI, A. (Ri)costruire la professionalità degli insegnanti. Annali dell'Istruzzione. La formazione degli insegnanti nella scuola della reforma, n. 1/2, Año XLXIX, Le Monnier, p. 159-165, 2003.

CERVINI, R. Diferencias de resultados cognitivos y no-cognitivos entre estudiantes de escuelas públicas y privadas en la educación secundaria de Argentina: Un análisis multinivel. Education Policy Análisis Archives, v. 11, n. 6, 2003. Disponível em: <http:// epaa.asu.edu/epaa/v11n6/>.

DE CLOSETS, F. Le bonheur d'apprendre. Et comment on le tue. Paris: Fayard, 1996.

DUBET, F. L'expérince sociologique. Paris : La Découverte, 2007.

DUBET, F. Le declin de l'institution. Paris : Senil, 2002.

ELIAS, N. La generación de los padres y otros ensayos. Barcelona, 1997.

IIPE/UNESCO. Los docentes y los desafios de la profesionalización. Informe, v. II. Buenos Aires, 2000.

MARCHESI, A. Cambios sociales, emociones y los valores de los docentes. In: TENTI FANFANI, E. (Comp.). Nuevos tiempos y temas de la agenda de política educativa. Siglo XXI, 2008.

PASSERON, J. C. Le sociologue en politique et viceversa. Les enquetes sociologiques et la reforme pedagogique dans les annees 60. Doc. Inedito. College de France, Paris juin-novembre, 2003.

PERELMAN, L. L. La escuela actual es tan productive como un Kolkhoze. Courrier Internacional, n. 255, 21 al 27 de setiembre, 1995.

POLANYI, M. La società libera. Roma: Armando Editore, 2006.

SIMONE, R. Il mostro mite. Perché l'Occidente no va a sinistra. Milán: Garzanti, 2008.

TEDESCO, J. C.; LOPEZ, N. Desafíos a la Educación Secundaria en América Latina. Revista de la CEPAL, Santiago de Chile, n. 76, Abril, 2002.

TENTI FANFANI, E. La condición docente. Análisis comparado de la Argentina, Brasil, Perú y Uruguay. Buenos Aires: Editorial Siglo XXI, 2005.

TENTI FANFANI, E. Educación media para todos. Los desafíos de la democratización del acceso. (compilador y autor del capítulo I). Buenos Aires: Altamira, 2003. 
TENTI FANFANI, E. Prologo. In: KESSLER G. La experiencia escolar fragmentada. Buenos Aires: IIPE/UNESCO, 2002.

TENTI FANFANI, E. Una escuela para los adolescentes. Buenos Aires: Losada, 1999.

TIRAMONTI, G. Y.; ZIEGLER, S. La educación de las elites. Aspiraciones, estrategias y oportunidades. Buenos Aires: Paidós, 2008.

TODOROV, T. La littérature en péril. Paris : Flammarion, 2007.

VIRNO, P. Gramatica de la multitud. Para un analisis de las formas de vida contemporanea. Buenos Aires: Granica, 2003.

\section{APÉNDICE}

\begin{tabular}{|l|c|c|c|}
\hline & Maestro & Profesor & Total \\
\hline Quintil 1 & 9,1 & 2,3 & $\mathbf{6 , 0}$ \\
Quintil 2 & 17,4 & 10,2 & $\mathbf{1 4 , 1}$ \\
Quintil 3 & 30,4 & 26,6 & $\mathbf{2 8 , 6}$ \\
Quintil 4 & 28,5 & 32,5 & $\mathbf{3 0 , 3}$ \\
Quintil 5 & 14,6 & 28,4 & $\mathbf{2 0 , 9}$ \\
Total & $\mathbf{1 0 0}$ & $\mathbf{1 0 0}$ & $\mathbf{1 0 0}$ \\
\hline
\end{tabular}

CUADRO 1 - DISTRIBUCIÓN DE MAESTROS Y PROFESORES EN LA ESTRUCTURA QUINTÍLICA DE INGRESOS PER CÁPITA DEL HOGAR DEL CONJUNTO URBANO DE LA ARGENTINA

Texto recebido em janeiro de 2010.

Texto aprovado em junho de 2010. 


\begin{tabular}{|l|c|c|c|c|c|c|c|c|c|}
\hline & \multicolumn{3}{|c|}{ Poseen automóvil en la casa } & \multicolumn{3}{c|}{ Poseen computadora en la casa } & \multicolumn{3}{|c|}{ Poseen acceso a Internet en la casa } \\
\cline { 2 - 10 } & Maestro & Profesor & Total & Maestro & Profesor & Total & Maestro & Profesor & Total \\
\hline GBA & 38,7 & 53,3 & 44,3 & 50,8 & 75,0 & 60,0 & 22,6 & 39,5 & 29,0 \\
Pampeana & 54,7 & 69,6 & 62,2 & 43,7 & 71,8 & 57,8 & 13,2 & 20,3 & 16,8 \\
NEA & 44,5 & 49,2 & 46,9 & 32,5 & 43,9 & 38,3 & 4,4 & 13,3 & 8,9 \\
NOA & 29,2 & 53,2 & 41,1 & 25,4 & 51,2 & 38,1 & 4,2 & 11,5 & 7,8 \\
Cuyo & 60,8 & 73,6 & 68,2 & 45,3 & 70,1 & 59,5 & 13,6 & 25,7 & 20,5 \\
Patagonia & 58,4 & 67,9 & 62,9 & 51,6 & 65,1 & 57,9 & 15,8 & 26,5 & 20,8 \\
Total & $\mathbf{4 6 , 0}$ & $\mathbf{6 2 , 0}$ & $\mathbf{5 3 , 5}$ & $\mathbf{4 3 , 7}$ & $\mathbf{6 6 , 9}$ & $\mathbf{5 4 , 6}$ & $\mathbf{1 4 , 9}$ & $\mathbf{2 4 , 1}$ & $\mathbf{1 9 , 2}$ \\
\hline
\end{tabular}

CUADRO 2 - DISPONIBILIDAD DE CIERTOS BIENES Y SERVICIOS POR PARTE DE MAESTROS Y PROFESORES, SEGÚN REGIÓN DEL PAÍS

\begin{tabular}{|l|c|c|c|c|c|c|}
\hline \multirow{2}{*}{$\begin{array}{l}\text { Nivel socio } \\
\text { económico }\end{array}$} & \% fila & \% col. & \% fila & \% col. & \% fila & \% col. \\
\cline { 2 - 7 } Bajo & 72,5 & 36,4 & 27,5 & 15,6 & 100,0 & 26,6 \\
Medio bajo & 60,9 & 27,2 & 39,1 & 19,8 & 100,0 & 23,7 \\
Medio alto & 44,6 & 21,5 & 55,4 & 30,2 & 100,0 & 25,6 \\
Alto & 32,9 & 14,9 & 67,1 & 34,4 & 100,0 & 24,1 \\
Total & $\mathbf{5 3 , 1}$ & $\mathbf{1 0 0 , 0}$ & $\mathbf{4 6 , 9}$ & $\mathbf{1 0 0 , 0}$ & $\mathbf{1 0 0 , 0}$ & $\mathbf{1 0 0 , 0}$ \\
\hline
\end{tabular}

CUADRO 3 - MAESTROS Y PROFESORES SEGÚN NIVEL SOCIOECONÓMICO

\begin{tabular}{|l|c|c|c|}
\hline & Maestro & Profesor & Total \\
\hline GBA & 4,4 & 2,5 & $\mathbf{3 , 7}$ \\
Pampeana & 7,6 & 0,6 & $\mathbf{4 , 2}$ \\
NEA & 20,8 & 9,7 & $\mathbf{1 4 , 9}$ \\
NOA & 36,2 & 11,6 & $\mathbf{2 3 , 3}$ \\
Cuyo & 13,2 & 2,9 & $\mathbf{7 , 3}$ \\
Patagonia & 5,8 & 1,6 & $\mathbf{3 , 9}$ \\
Total & $\mathbf{1 1 , 6}$ & $\mathbf{4 , 2}$ & $\mathbf{8 , 1}$ \\
\hline
\end{tabular}

CUADRO 4 - INCIDENCIA DE LA POBREZA ENTRE MAESTROS Y PROFESORES SEGÚN REGIÓN DEL PAÍS 


\begin{tabular}{|l|c|c|c|}
\hline & Total & Primaria & Secundaria \\
\hline Mejor & 29,8 & 27,4 & 32,8 \\
Peor & 28,4 & 28 & 28,8 \\
Igual & 37,7 & 40,8 & 33,9 \\
Ns/nc & 4,1 & 3,8 & 4,5 \\
Total & 100 & 100 & 100 \\
\hline
\end{tabular}

CUADRO 5 - PERCEPCIÓN DE LOS DOCENTES SOBRE SU CONDICIÓN ECONÓMICA CON RESPECTO A SUS PADRES SEGÚN NIVEL DE ENSEÑANZA

\begin{tabular}{|lcc|c|}
\hline & Maestros & Profesores & Total \\
\hline Tiempo disponible para corregir cuadernos, trabajos, etc. & 68,3 & 70,2 & 69,2 \\
El tiempo disponible para desarrollo de tareas & 54,6 & 61,7 & 57,9 \\
La falta de definiciones y objetivos claros & 47,6 & 63,3 & 55,0 \\
Disponibilidad de ámbitos de asesoramiento y supervisión & 49,9 & 57,0 & 53,2 \\
Las características sociales de los alumnos & 48,3 & 53,2 & 50,6 \\
Manejar la disciplina en clase & 32,0 & 34,2 & 33,0 \\
La relación con los padres & 22,4 & 35,9 & 28,7 \\
Evaluar & 18,9 & 23,7 & 21,2 \\
Las formas de planificar & 16,4 & 24,3 & 20,1 \\
El dominio de los nuevos contenidos & 8,5 & 12,0 & 10,1 \\
Organizar el trabajo en clase & 7,3 & 10,6 & 8,9 \\
La relación con los directivos & 6,9 & 9,4 & 8,1 \\
El trabajo con los colegas & 6,3 & 9,5 & 7,8 \\
\hline
\end{tabular}

CUADRO 6 - \% DE MAESTROS Y PROFESORES QUE SEÑALAN COMO PROBLEMÁTICOS DIFERENTES ASPECTOS DE LA ACTIVIDAD DOCENTE 


\begin{tabular}{|l|c|c|c|c|c|}
\hline & Se fortalece & $\begin{array}{c}\text { Se mantiene } \\
\text { estable }\end{array}$ & Se debilita & No se & Total \\
\hline El compromiso social & 6,3 & 12,9 & 73,7 & 7,1 & $\mathbf{1 0 0}$ \\
La responsabilidad & 3,3 & 12,6 & 80,0 & 4,1 & $\mathbf{1 0 0}$ \\
El sentido de familia & 3,4 & 16,8 & 75,9 & 3,8 & $\mathbf{1 0 0}$ \\
La seriedad & 2,0 & 14,6 & 75,9 & 7,5 & $\mathbf{1 0 0}$ \\
La espiritualidad & 5,5 & 19,8 & 64,8 & 10,0 & $\mathbf{1 0 0}$ \\
La honestidad & 4,0 & 22,7 & 67,5 & 5,8 & $\mathbf{1 0 0}$ \\
El amor a la libertad & 32,6 & 39,5 & 21,5 & 6,4 & $\mathbf{1 0 0}$ \\
La identidad nacional & 5,4 & 20,9 & 67,4 & 6,2 & $\mathbf{1 0 0}$ \\
La generosidad y el desinterés & 6,2 & 29,1 & 57,6 & 7,1 & $\mathbf{1 0 0}$ \\
El sentido del deber & 2,7 & 13,7 & 78,1 & 5,5 & $\mathbf{1 0 0}$ \\
El respeto a los mayores & 2,1 & 12,1 & 81,4 & 4,4 & $\mathbf{1 0 0}$ \\
El cuidado de la naturaleza & 32,0 & 21,2 & 41,8 & 5,0 & $\mathbf{1 0 0}$ \\
El sentido de justicia & 21,0 & 20,9 & 52,3 & 5,8 & $\mathbf{1 0 0}$ \\
La tolerancia & 6,4 & 18,4 & 69,7 & 5,4 & $\mathbf{1 0 0}$ \\
La disposición al esfuerzo & 2,9 & 13,4 & 78,2 & 5,5 & $\mathbf{1 0 0}$ \\
\hline
\end{tabular}

CUADRO 7 - OPINIONES ACERCA DEL FORTALECIMIENTO O DEBILITAMIENTO DE VALORES EN LA JUVENTUD

\begin{tabular}{|c|c|c|c|c|c|c|c|}
\hline & $A M B A$ & Pampeana & Noreste & Noroeste & Cuyo & Patagonia & Total \\
\hline \multicolumn{8}{|l|}{ Actitud negativa } \\
\hline Alta & 28,8 & 30,7 & 42,5 & 38,1 & 39,2 & 36,4 & 33 \\
\hline Media & 32,3 & 33,6 & 31,4 & 28,9 & 30,5 & 28 & 31,9 \\
\hline Baja & 39 & 35,6 & 26,2 & 33 & 30,3 & 35,6 & 35,1 \\
\hline Total & 100 & 100 & 100 & 100 & 100 & 100 & 100 \\
\hline
\end{tabular}

CUADRO 8 - GRADO DE ACTITUD NEGATIVA DE LOS DOCENTES EN RELACIÓN CON LOS JÓVENES POR REGIÓN (EN PORCENTAJES)

\begin{tabular}{|c|c|c|c|}
\hline & & \multicolumn{2}{|c|}{ Tipo de gestión } \\
\hline & & Pública & Privada \\
\hline \multicolumn{4}{|c|}{ Actitud negativa } \\
\hline & Alta & 33,9 & 30 \\
\hline & Media & 32,7 & 29,6 \\
\hline & Baja & 33,5 & 40,4 \\
\hline Total & & 100 & 100 \\
\hline
\end{tabular}

CUADRO 9 - GRADO DE ACTITUD NEGATIVA DE LOS DOCENTES EN RELACIÓN CON LOS JÓVENES POR TIPO DE GESTIÓN DE LOS ESTABLECIMIENTOS (EN PORCENTAJE) 